IZA DP No. 9972

Job Creation in a Multi-Sector Labor Market Model for Developing Economies

Arnab K. Basu

Nancy H. Chau

Gary S. Fields

Ravi Kanbur

May 2016 


\title{
Job Creation in a Multi-Sector Labor Market Model for Developing Economies
}

\author{
Arnab K. Basu \\ Cornell University and IZA
}

Nancy H. Chau

Cornell University and IZA

Gary S. Fields

Cornell University, IZA and WIDER

Ravi Kanbur

Cornell University and IZA

Discussion Paper No. 9972

May 2016

IZA

P.O. Box 7240

53072 Bonn

Germany

Phone: +49-228-3894-0

Fax: +49-228-3894-180

E-mail: iza@iza.org

\begin{abstract}
Any opinions expressed here are those of the author(s) and not those of IZA. Research published in this series may include views on policy, but the institute itself takes no institutional policy positions. The IZA research network is committed to the IZA Guiding Principles of Research Integrity.

The Institute for the Study of Labor (IZA) in Bonn is a local and virtual international research center and a place of communication between science, politics and business. IZA is an independent nonprofit organization supported by Deutsche Post Foundation. The center is associated with the University of Bonn and offers a stimulating research environment through its international network, workshops and conferences, data service, project support, research visits and doctoral program. IZA engages in (i) original and internationally competitive research in all fields of labor economics, (ii) development of policy concepts, and (iii) dissemination of research results and concepts to the interested public.
\end{abstract}

IZA Discussion Papers often represent preliminary work and are circulated to encourage discussion. Citation of such a paper should account for its provisional character. A revised version may be available directly from the author. 


\section{ABSTRACT}

\section{Job Creation in a Multi-Sector Labor Market Model for Developing Economies*}

This paper proposes an overlapping generations multi-sector model of the labor market for developing countries with three heterogeneities - heterogeneity within self-employment, heterogeneity in ability, and heterogeneity in age. We revisit an iconic paradox in a class of multi-sector labor market models in which the creation of high-wage employment exacerbates unemployment. Our richer setting allows for generational differences in the motivations for job search to be reflected in two distinct inverted U-shaped relationships between unemployment and high-wage employment, one for youth and a different one for adults. In turn, the relationship between overall unemployment and high-wage employment is shown to be non-monotonic and multi-peaked. The model also sheds light on the implications of increasing high-wage employment on self-employed workers, who make up most of the world's poor. Non-monotonicity in unemployment notwithstanding, increasing high-wage employment has an unambiguous positive impact on high-paying self-employment, and an unambiguous negative impact on free-entry (low-wage) self-employment.

JEL Classification: $\quad 017,132$

Keywords: multisector labor market, overlapping generations, poverty reduction, Harris-Todaro model

Corresponding author:

Nancy H. Chau

Charles H. Dyson School of Applied Economics and Management

Cornell University

Ithaca, NY 14853

USA

E-mail: hyc3@cornell.edu

* We thank Juan David Robalino for outstanding research assistance in the preparation of this version. 


\section{Introduction}

Does increasing high-wage employment increase or decrease unemployment? What does increasing high-wage employment do to youth and adult unemployment? What does increasing high-wage employment do to high-paying self-employed and low-wage free-entry work? These questions, and others like them, will be recognized as being important in the policy debates in developing countries. Can our models address them?

The need for labor market models which stylize the reality of developing country conditions in tractable form in order to allow analysis of a range of policy questions, has been central to the development economics field for decades. Among the most important contributions are the Lewis model (Lewis, 1954), which won its developer the Nobel Prize, and the Harris-Todaro model (Harris and Todaro, 1970), which was honored as being one of the top twenty articles published in the American Economic Review in the last century. What both these models have at their core is multiple labor markets, each working in its own way and connected to the other. Both models also feature labor market segmentation, which we define consistent with the literature as arising when: i) the same worker can earn more in some segments of the economy than he/she could earn in other segments, and ii) access to the better-paying segments is rationed, so that not all workers who would like to work in the good jobs part of the economy and who are capable of performing those jobs can in fact get such jobs.

The iconic and counterintuitive answer of the Harris-Todaro model to the first question posed at the beginning of this introduction is of course that increasing high-wage employment will increase unemployment. ${ }^{1}$ But it should be clear that neither the Lewis model nor the Harris-Todaro model can in fact address the remaining questions, because they do not incorporate features of developing countries which underpin those questions. We therefore need models which incorporate these realities in sufficiently tractable form that the full range of questions can be addressed.

In the intervening decades since Lewis and Harris and Todaro did their work, it has become widely (though not universally) accepted that labor markets in developing economies have multiple segments (as opposed to one single set of conditions applying to all) and that labor markets are segmented according to the preceding definition (i.e., i) the same worker can earn more in some segments of the economy than in others and ii) access to the better-paying segments is rationed). Lewis (1954) had high-wage work and low-wage work coexisting, but unemployment was missing from his

\footnotetext{
${ }^{1}$ The Todaro Paradox has inspired a large literature (e.g. Zarembka 1970, Arellano 1981, and more recently Zenou 2011). Also see a survey of the literature in Lall, Selod and Shalizi (2006).
} 
model. On the other hand, Todaro (1969) conflated everyone not employed in the high-wage sector into a single category called "urban traditional sector". Harris and Todaro (1970) had three employment states - high-wage work and unemployment in urban areas, plus low-wage work in rural areas. Subsequent models developed by Fields $(1975,1989)$ and others (e.g., Steel and Takagi, 1983) had both unemployment and low-wage work in urban areas in addition to high-wage urban employment. Banerjee and Newman (1993) had four occupational options - subsistence work, work as a wage laborer, self-employment, and entrepreneurship - but no unemployment.

Based on evidence accumulated to date, particularly at the micro-level, it has also become clear that a number of additional salient empirical features of developing country labor markets are at odds with the assumptions / implications of these earlier models. In this paper, we introduce three such features which allow us to answer the full range of questions posed at the start.

The first heterogeneity observed in the world and modeled here is duality within selfemployment. Some people are self-employed because i) they would like to work in the advantaged segments of the labor market, but access to those jobs is rationed, and ii) they cannot afford to search for long for jobs in the advantaged segments, instead preferring to take up easy-entry jobs which they often create themselves. These people have been variously referred to as "microenterprise operators," "penniless entrepreneurs", the "reluctant self-employed", "free-entry workers", and "informal workers", among others. Such people, for example, make their living by buying cigarettes twenty at a time and selling them at a higher unit price to others who are so poor that they can only buy cigarettes when they can scrape together enough cash to buy a single one. On the other hand, there are others who had been wage employees in the advantaged segments and could have remained there who choose to leave such jobs and set up their own self-employment activities. A former Ford garage worker who accumulates skills and saves up to buy his own tools, then leaves to set up his own backyard auto mechanic shop, is an example. The empirical literature agrees with the co-existence of - and the distinction between - workers "excluded" and "exited" from wage employment among the selfemployed (Perry et al., 2007), but disagrees about the relative importance of the two (Fields, 1990; Maloney, 2004). The theoretical literature, however, has yet to incorporate these two types of selfemployment - the low wage free entry self-employed who are excluded from wage employment, and the high-paying self-employed who exited wage employment - into the same model. ${ }^{2}$

\footnotetext{
${ }^{2}$ Bennett and Rablen (2012) introduce heterogeneity in the informal sector by incorporating informal wage employment, self-employment, and informal entrepreneurship, defined as establishments that offer (informal) wage employment to no greater than a critical threshold number of workers. Unlike our model, the BennettRablen model assumes that there is no unemployment. Furthermore, selection into informal wage employment,
} 
A second feature of the world that we bring into our analysis is differences in worker abilities. Such differences have been incorporated into the work of Nobel Prize winners including the human capital models of Schultz (1961) and Becker (1964), the signaling model of Spence (1973), the screening model of Stiglitz (1975), and the rat-race model of Akerlof (1976). An early model of education markets interacting with segmented labor markets is Fields $(1974,1975)$. In this paper, we depart from the earlier theoretical literature by recognizing that workers differ in terms of their abilities to earn money in self-employment and model these differences as a continuum of abilities.

The third feature of the world which we incorporate into our model is differences in worker capital, whether human or physical, that can evolve over time with the accumulation of job experience. Evidence from extensive interviews (Balan, Browning, and Jelin, 1973; Fields, 1990; Maloney, 2004), as well as individual profiles of self-employed workers (Jütting, Parlevliet and Xenogiani, 2008) argues in favor of a "lifecycle" model, in which for a young worker, wage employment makes possible the accumulation of skills and savings that can be later on used to enter the upper tier of self-employment. Actual transitions from wage employment to high wage self-employment in turn depend on the juxtaposition of accumulated skill and / or savings, as well as worker-specific gains / satisfaction from upper tier self-employment. The implications in terms of modeling are two-fold: 1) For each worker, the decision making calculus related to transitions between employment states must now be amended to account for lifetime utility consequences. 2) Across individuals in each employment state at any single point in time, comparative statics of labor market outcomes must now keep track of overlapping generations of youths and adults both working in the labor market. All of these considerations have hitherto been absent from the theoretical literature.

In this paper, we build a model incorporating the preceding stylized features of developing country labor markets including the "three heterogeneities": duality within self-employment; a continuum of abilities among workers; and the presence of both younger and older workers in the labor force. The model has four labor market states: three employment sectors - termed wage employment, free-entry self-employment, and high-wage self-employment - plus unemployment. Workers choose among two search strategies: a risky search strategy, which results in wage employment if successful but unemployment if unsuccessful, and a safe search strategy, which results in free-entry self-employment (but at low wages) with certainty. Further, we assume that a worker has to spend some time in the wage

self- employment, and entrepreneurship depends only on the skills of individual workers, and thus segmentation within the informal sector between upper and lower tier (self-)employment, the main point of departure of our model from the literature, is ruled out. Heterogeneity of the informal sector, and the need for recognition by analysts and policy makers, has been stressed by Chen (2006). 
employment sector in order to acquire skills and finance to make entrepreneurship feasible. But individuals differ in their abilities as entrepreneurs and this is a further factor in their decisions on search strategy. This also highlights the time dimension of the model-workers live for two periods, and can make rational choices regarding job search in each of these periods. The distinction between youth and older workers thus emerges as a natural feature of the model.

In the model, we allow for a large number of workers making such choices and facing such constraints. We solve for the market equilibrium of the model. The solution is sufficiently tractable that a range of comparative static exercises can be carried out. These comparative static exercises will in turn provide answers to the three questions we pose at the outset.

The plan of the paper is as follows. Section 2 sets out the model, incorporating key extensions to the basic Harris-Todaro structure. Section 3 develops the equilibrium, taking into account rational decisions of young and old, and balance in labor flows throughout the economy. We show that despite adding extensions and modifications to the basic Harris-Todaro structure we are able to derive tractable results. Section 4 provides a discussion of the comparative statics of the model. Section 5 concludes the paper. 


\section{Model}

\subsection{Setup of the Model}

In what follows, we describe the conditions characterizing a multi-sector labor market in a steady state, in the sense that the labor allocations across search strategies ex ante and labor market states ex post, to be described below, remain constant over time.

\section{Overlapping Generations and Workforce}

The economy is made up of overlapping generations of workers with two-period lives (youth and adulthood). Youth are denoted by small letters, adults by capital letters, and total by script capital letters. So, for example, $e_{j}$ denotes the employment of youth in sector $j, E_{j}$ denotes the employment of adults in sector $j$, and $\mathcal{E}_{j}=e_{j}+E_{j}$. Workers work during both periods of their lives, and $\rho$ denotes the discount factor. The number of workers in each generation will be denoted as $\mathcal{L}$. The size of the economy's workforce, including young and adult workers, is thus $2 \mathcal{L}$ in every period.

\section{Sectors of Employment and Wages in Each}

The economy has three sectors of employment, respectively termed wage employment $\left(\mathcal{E}_{W}=E_{W}+\right.$ $\left.e_{W}\right)$, free-entry self-employment $\left(\varepsilon_{F}=E_{F}+e_{F}\right)$, and high-paying self-employment $\left(\varepsilon_{H}=E_{H}+e_{H}\right)$. Unemployment $(U=U+u)$ constitutes a fourth labor market state. Once a worker finds employment in a sector, he can keep that employment for the two periods of his life, i.e. there is no involuntary labor turnover.

Wages and employment are determined as follows. In the wage employment sector $(W)$, employers set the wage, $w_{W}$, exogenously at a level above that of the other two sectors. This may be for market reasons (i.e., efficiency wages), institutional reasons (e.g., minimum wages, labor unions), or a combination of the two. Adults and youth are perfect substitutes in production, and therefore employers are indifferent between hiring an adult and hiring a youth for any job vacancy. Employers demand workers $\left(\varepsilon_{W}=E_{W}+e_{W}\right)$ such that the net labor cost $w_{W}$ equals the marginal product of the last worker hired:

$$
\mathcal{E}_{W}\left(w_{W}, a_{W}\right)=\left\{\varepsilon_{W} \mid \partial G\left(\varepsilon_{W}, a_{W}\right) / \partial \mathcal{E}_{W}=w_{W}\right\},
$$


where total revenue in the wage employment sector $G\left(\varepsilon_{W}, a_{W}\right)$ exhibits positive and strictly decreasing marginal value product of labor. $a_{W}$ is a wage employment demand shifter, with $\partial^{2} G\left(\varepsilon_{W}, a_{W}\right) /$ $\partial \mathcal{E}_{W} \partial a_{W}>0$. From (1), $\varepsilon_{W}\left(w_{W}, a_{W}\right)$ is strictly increasing in $a_{W}$ at constant $w_{W} \cdot{ }^{3}$

The free-entry sector, $F$, is one where any worker who desires a job can find one. The free-entry wage is assumed invariant to the number of workers in the sector. This wage is denoted by $w_{F}$.

The high-paying self-employment sector, $H$, is not free entry. An important innovation of this paper is that in order to have the skills and resources to enter high-paying self-employment, a worker must have worked in the wage employment sector for at least one period. Therefore, all workers in the high-paying self-employment sector are adults, but not all adults are able to enter this sector, or if able, not all choose to.

Whether a worker with the skills and resources to enter high-paying self-employment chooses to enter or not depends on how high the pay is for that worker, which in turn depends on an individual productivity / utility parameter $\theta$, which is known to the worker. $\theta$ in each generation is distributed uniformly and symmetrically around zero, with $\theta \in[-\bar{\theta}, \bar{\theta}]$. If a worker with the required skills and resources chooses to engage in high-paying self-employment, he would earn what he would have earned had he remained in wage employment $\left(w_{W}\right)$ plus the individual-specific money equivalent wage income for him. Only workers who would earn more in high-paying self-employment than in wage employment would choose to leave wage employment in favor of high-paying self-employment.

A worker who enters high-paying self-employment would earn $w_{W}+\theta$. Given high-paying selfemployment lasts one period -- adulthood -- the marginal worker who is just indifferent between wage employment and high-paying self-employment is endowed with a $\hat{\theta}$ defined implicitly as $w_{W}+\hat{\theta}=w_{W}$, or equivalently

$$
\hat{\theta}=0
$$

\section{Choosing Among Search Strategies}

In order to select between search strategies, workers (both adult and young) evaluate the expected values associated with each strategy and choose whichever is higher. Let $V_{i}$ and $v_{i}$ denote the expected values

\footnotetext{
${ }^{3}$ To see this, note from (1) that

$$
\frac{\partial \varepsilon_{W}\left(w_{W}, a_{W}\right)}{\partial a_{W}}=-\frac{\partial^{2} G\left(\varepsilon_{W}, a_{W}\right)}{\partial \varepsilon_{W} \partial a_{W}} / \frac{\partial^{2} G\left(\varepsilon_{W}, a_{W}\right)}{\partial \varepsilon_{W} \partial \varepsilon_{W}}>0 .
$$
}


of search strategy $i=r, s$ facing adult and young workers respectively. Also let $J_{i}$ and $j_{i}$ denote the number of adult and young workers respectively who adopt the risky search strategy, and also denote $\mathcal{J}_{r}=J_{r}+j_{r}$.

Let us start with an adult worker who is not yet in high wage employment and who adopts the risky search strategy. The expected value associated with this search strategy is the wage in wage employment, if successful, multiplied by the probability of success:

$$
V_{r}=\pi w_{W}
$$

Observe that since adults have only one period of work life remaining, the possibility of entering high paying self-employment does not arise, and therefore $V_{r}(\pi)$ is independent of the payoff to that worker of being in high paying self-employment.

Employers are assumed to choose randomly from among the pool of workers who have adopted the risky search strategy, who will be called risky job seekers, to fill any job opening in the wage employment sector. Each risky job seeker faces the same probability of being hired for wage employment as any other; this probability is given by

$$
\pi=\frac{\text { job openings in wage employment }}{\text { total number of risky job seekers }} .
$$

Both the numerator and the denominator on the right hand side are determined by a set of complicated relationships that will be explained in detail later.

For an adult worker who adopts the safe search strategy, the expected value is simply the wage in the free-entry sector:

$$
V_{s}=w_{F}
$$

Now for a young worker who adopts the risky strategy, the expected value $v_{r}$ depends on whether he is a high $\theta$ or a low $\theta$ worker. For a high $\theta$ worker who adopts the risky search strategy, he finds wage employment at $w_{W}$ as a young worker with probability $\pi$, knowing that a period later, he will move into high-paying self-employment at $w_{W}+\theta$. If he adopts the risky search strategy and is unsuccessful, which occurs with probability $1-\pi$, the young worker is unemployed for one period, but retains the option to choose between the two search strategies once again a period later as an adult. The associated option value is $\max \left\{V_{r}, V_{s}\right\}$, appropriately discounted by the discount factor $\rho$. Now for a low $\theta$ young worker who adopts the risky search strategy, with probability $\pi$ he will obtain a job in the 
high wage sector in the first period of his life and will retain that job in the second period of his life, thus earning $w_{W}$ in both periods. If such a worker is unsuccessful in period 1 , which occurs with probability $1-\pi$, the worker is unemployed for that period, and a period later, he can again choose between the risky and the safe strategies, with associated value $\max \left\{V_{r}, V_{s}\right\}$, appropriately discounted. In summary, for a young person entering the labor market for the first time,

$$
v_{r}(\pi, \theta)=\left\{\begin{array}{lr}
\pi\left[w_{W}+\rho\left(w_{W}+\theta\right)\right]+(1-\pi) \rho \max \left\{V_{r}(\pi), V_{s}\right\} & \text { if } \theta>\hat{\theta} \\
\pi\left[w_{W}(1+\rho)\right]+(1-\pi) \rho \max \left\{V_{r}(\pi), V_{s}\right\} & \text { otherwise }
\end{array}\right.
$$

Observe that $v_{r}(\pi, \theta)$ is continuous in $\theta$, strictly increasing in $\theta$ among high $\theta$ workers, and independent of $\theta$ among low $\theta$ workers. In other words, comparing high and low $\theta$ workers, high $\theta$ workers derive larger benefits from the risky strategy than do low $\theta$ workers.

Turning now to a young worker who adopts the safe search strategy in period 1, this worker is guaranteed a period 1 income of $w_{F}$ in the free-entry sector. In period 2, the worker chooses between the two search strategies again, and this offers $\max \left\{V_{r}(\pi), V_{S}\right\}$. To a young worker, the expected value of adopting the safe search strategy in period 1 (though not necessarily in period 2 ) is thus

$$
v_{S}(\pi)=w_{F}+\rho \max \left\{V_{r}(\pi), V_{s}\right\}
$$

This concludes the setup of the model.

\section{Equilibrium}

A steady state equilibrium in this economy is a time invariant allocation of adult and young workers' ex ante search strategies $\left(\mathcal{J}_{r}^{*}=J_{r}^{*}+j_{r}^{*}\right)$, and a time invariant allocation of adult and young workers' ex post employment outcomes $\left(\mathcal{E}_{W}^{*}=E_{W}^{*}+e_{W}^{*}, \mathcal{E}_{F}^{*}=E_{F}^{*}+e_{F}^{*}, \mathcal{E}_{H}^{*}=E_{H}^{*}+e_{H}^{*}\right.$, and $\left.\mathcal{U}^{*}=U^{*}+u^{*}\right)$ such that (i) each worker chooses a search strategy that maximizes expected utility (equations (3), (5) - (7)) conditional on the probability of wage employment facing risky job seekers (equation (4)), (ii) employers make wage employment decisions according to equation (1), (iii) workers in high-paying selfemployment receive wages according to equation (2), and (iv) workers in free entry self-employment receive $w_{F}$. 
We begin our analysis with an examination of the choice between risky and safe search strategies by adult as well as young workers.

\section{Search Behavior as a Function of Age and Payoff to High-Paying Self-Employment $(\theta)$}

Given the returns in the preceding section, which types of worker -- young or old, high $\theta$ or low $\theta$-- will adopt the risky search strategy in which order?

The first to adopt risky search are the young high $\theta$ workers starting with the highest $\theta$

individual (i.e., the one with $\theta=\bar{\theta}$ ) followed next by other high $\theta$ young workers with successively lower $\theta^{\prime}$ s until we have gotten to the young individual whose $\theta=0$. The reason the first group of risky job seekers are young workers rather than adult workers is that young workers have two periods of highpaying work after a successful risky search, compared to adult workers who have only one period of work life remaining. The reason young workers engage in risky search in decreasing order of $\theta$ is that young workers with higher $\theta$ 's would earn more in high-paying self-employment than would lower $\theta$ workers.

The next workers in line to adopt the risky search strategy are young low $\theta$ workers. Within that group, start with one individual, whose value of $\theta$ is indeterminate. More and more individuals within this group will engage in risky search until all do. The reason $\theta$ does not matter is that young low $\theta$ workers seek wage employment with the intention of staying in wage employment for two periods and not entering self-employment, and so the specific value of $\theta$, which determines how much they would earn in self-employment, is irrelevant. The reason these low $\theta$ young workers will adopt risky search before any adult workers do, even the highest $\theta$ adult, is that low $\theta$ young workers have two periods of high-paying work after a successful risky search compared to an adult worker who receives a payoff for one period only.

The last workers to choose risky search are older workers. The values of $\theta$ do not matter for these adult workers, since the successful ones will work in wage employment for one period only, after which they must retire; they will never have the chance to work in high wage self-employment.

The proof that workers will engage in risky search in the order discussed in the three preceding paragraphs is as follows. The expected value gain from adopting the risky search strategy rather than the safe search strategy is $v_{r}(\pi, \theta)-v_{S}(\pi)$ for young workers, and $V_{r}(\pi)-V_{S}$ for adult workers. The difference between these two expected value gains $v_{r}(\pi, \theta)-v_{S}(\pi)-\left[V_{r}(\pi)-V_{s}\right]$ for all $\theta \in[-\bar{\theta}, \bar{\theta}]$ and $\pi \leq 1$, can be written as 


$$
\begin{aligned}
& v_{r}(\pi, \theta)-v_{S}(\pi)-\left[V_{r}(\pi)-V_{S}\right] \\
& =\pi \rho\left[w_{W}-\max \left\{\pi w_{W}, w_{F}\right\}+\max \left\{0, w_{W}+\theta-w_{W}\right\}\right] \\
& =\pi \rho\left[\min \left\{(1-\pi) w_{W}, w_{W}-w_{F}\right\}+\max \{0, \theta\}\right] .
\end{aligned}
$$

The last line can be seen to be a positive number as long as the wage in the free-entry sector, $w_{F}$, does not exceed the wage in wage employment $w_{W}$-- an assumption we have maintained from the outset which proves that young workers will engage in risky search before adult workers do. In addition, the last term in the last line is increasing in $\theta$ for high $\theta$ workers, for whom $\max \{0, \theta\}=\theta$, which proves that young high $\theta$ workers engage in risky search before young low $\theta$ workers. Then, young low $\theta$ workers start engaging in risky search. For them, $\max \{0, \theta\}=0$. As well, for them, the difference $v_{r}(\pi, \theta)-v_{S}(\pi)-\left[V_{r}(\pi)-V_{S}\right]$ is simply $\pi \rho \min \left\{(1-\pi) w_{W}, w_{W}-w_{F}\right\}$ plus zero, also a positive number. This proves that young low $\theta$ workers will engage in risky search after young high $\theta$ workers do, but $\theta$ does not affect which workers are so engaged. Thus, we have shown that the expected value gain from risky search for all young workers exceeds the expected value gain from risky search for all adult workers, and therefore adult workers will adopt risky search only after all young workers have already adopted risky search. The order in which adult workers choose risky search is indeterminate because $V_{r}(\pi)$ and $V_{s}$ are both independent of $\theta$.

Following this order, we then have five regimes:

I. Some or all young high $\theta$ workers adopt risky search.

II. All young high $\theta$ workers and some but not all low $\theta$ workers adopt risky search.

III. All young workers and no adult workers adopt risky search.

IV. All young workers and some but not all adult workers adopt risky search.

V. All workers, young and adult alike, adopt risky search.

The set of five search behavior regimes discussed above is an exhaustive characterization of all of the possible equilibrium combinations of search behaviors among adult and young job seekers in this model. In this section, our tasks are two-fold. For each regime, we will first present closed form solutions for the equilibrium ex ante allocation of workers between the two search strategies and the associated probability of wage employment, conditional on the equilibrium occurring in that specific regime. Next, we seek the conditions under which an equilibrium will indeed arise in each of the five regimes, based on which a discussion of the uniqueness of equilibrium in this model will also be included. 


\section{Regime I: Only Young High $\theta$ Workers Adopt Risky Search}

A regime I equilibrium occurs when only young high $\theta$ workers adopt risky search, and the rest of the young workers and all adult workers adopt safe search. Denote the $\theta$ of the young high $\theta$ worker who is just indifferent between risky search and safe search as $\tilde{\theta}$. For this high $\theta$ worker, the expected value associated with risky search $v_{r}(\pi, \tilde{\theta})$ is equal to that of safe search $v_{S}(\pi)$. Furthermore, in a regime where only young high $\theta$ workers adopt risky search, our discussion in section 2.2 implies that for an adult the expected value associated with risky search $\left(V_{r}(\pi)=\pi w_{W}\right)$ must be less than that of safe search $\left(V_{s}=w_{F}\right)$. Thus, the $\theta$ of the indifferent worker, $\tilde{\theta}$, is implicitly defined by:

$$
\begin{aligned}
& v_{r}(\pi, \tilde{\theta})=v_{s}(\pi) \\
& \Leftrightarrow \pi\left[w_{W}+\rho\left(w_{W}+\tilde{\theta}\right)\right]+(1-\pi) \rho \max \left\{V_{r}(\pi), V_{S}\right\}=w_{F}+\rho \max \left\{V_{r}(\pi), V_{s}\right\} \\
& \Leftrightarrow \pi\left[w_{W}+\rho\left(w_{W}+\tilde{\theta}\right)\right]+(1-\pi) \rho V_{s}=w_{F}+\rho V_{s} \\
& \Leftrightarrow \pi\left[w_{W}+\rho\left(w_{W}+\tilde{\theta}\right)\right]+(1-\pi) \rho w_{F}=w_{F}+\rho w_{F} \\
& \Leftrightarrow \pi=\frac{w_{F}}{w_{W}+\rho\left(w_{W}+\tilde{\theta}-w_{F}\right)} .
\end{aligned}
$$

Given $\tilde{\theta}$, the total number of risky job seekers is equal to the number of high $\theta$ workers with $\theta$ at least as high as $\tilde{\theta}$, or:

$$
\mathcal{J}_{r}=\mathcal{L}\left(\frac{\bar{\theta}-\tilde{\theta}}{2 \bar{\theta}}\right)
$$

To determine the probability of wage employment in this regime $(\pi)$, recall (4):

$$
\pi=\frac{\text { job openings in wage employment }}{\text { total number of risky job seekers }} \text {. }
$$

The denominator, total number of risky job seekers, is as given by (9). The numerator, job openings in wage employment, is given by total wage employment demand $\mathcal{E}_{W}$ net of the number of wage employment stayers in each period. In regime I, in which only young high $\theta$ workers adopt risky search and do so with the intention of leaving wage employment to enter high-paying self-employment after one period of wage employment, the number of wage employment stayers is equal to zero. Thus,

$$
\text { job openings in wage employment }=\varepsilon_{W}-0=\mathcal{E}_{W} \text {. }
$$

Substituting (9) and (10) into the definition of $\pi$, we have

$$
\pi=\frac{2 \bar{\theta} \mathcal{E}_{W}}{\mathcal{L}(\bar{\theta}-\tilde{\theta})}
$$


in regime 1. Equations (8) and (11) are a pair of simultaneous equations in two unknowns $\tilde{\theta}$ and $\pi$. In what follows we will use an asterisk to denote equilibrium values. Solving (8) and (11), and substituting the solution $\tilde{\theta}^{*}$ back into (9), we obtain the equilibrium number of job seekers $\mathcal{J}_{r}^{*}$ :

$$
\mathcal{J}_{r}^{*}=\frac{\mathcal{E}_{W}\left(w_{W}+\rho\left(w_{W}+\bar{\theta}-w_{F}\right)\right)}{w_{F}+2 \mathcal{E}_{W} \rho \bar{\theta} / \mathcal{L}} .
$$

In addition, the corresponding equilibrium probability of wage employment is:

$$
\pi^{*}=\frac{w_{F}+2 \rho \bar{\theta} \varepsilon_{W} / \mathcal{L}}{w_{W}+\rho\left(w_{W}+\bar{\theta}-w_{F}\right)}
$$

if $\varepsilon_{W}$ is strictly positive, and zero otherwise. The closed form solutions in (12) and (13) show the equilibrium number of risky job seekers and the associated wage employment probability in a regime I equilibrium. To check the conditions under which a regime I equilibrium indeed applies, we need to verify that the equilibrium displayed in (12) - (13) above is indeed consistent with one where only young high $\theta$ workers adopt risky search, or equivalently, where $\mathcal{J}_{r}^{*}$ is less than the total number of high $\theta$ young workers, $L_{\text {high } \theta}=\mathcal{L} / 2$. From (12) and (8), $\mathcal{J}_{r}^{*}<L_{\text {high } \theta}$ if and only if

$$
\frac{\mathcal{E}_{W}\left(w_{W}+\rho\left(w_{W}+\bar{\theta}-w_{F}\right)\right)}{w_{F}+2 \mathcal{E}_{W} \rho \bar{\theta} / \mathcal{L}}<L_{\text {high } \theta} \Leftrightarrow \frac{\mathcal{E}_{W}}{\mathcal{L}}<\frac{1}{2} \frac{w_{F}}{w_{W}(1+\rho)-\rho w_{F}} \equiv \frac{\hat{\pi}}{2},
$$

where $\hat{\pi}$ is the highest value of $\pi$ consistent with a regime I equilibrium. As a necessary and sufficient condition for the equilibrium to occur in regime I, (14) requires that the likelihood of wage employment when all high $\theta$ young workers engage in risky search, or $\mathcal{E}_{W} / L_{\text {high } \theta}=\mathcal{E}_{W} /(\mathcal{L} / 2)$ from (11) evaluated at $\tilde{\theta}=0$, be sufficiently small. Specifically, $2 \mathcal{E}_{W} / \mathcal{L}$ should be smaller than $\hat{\pi}=w_{F} /\left(w_{W}(1+\rho)-\right.$ $\left.\rho w_{F}\right)$. Making use of (1), where the demand shifter $a_{W}$ denotes a factor that raises wage employment, the above condition requires that at given $w_{W}$ and at given total workforce $\mathcal{L}$ in each generation, the wage employment demand shifter $a_{W}$ must be small enough so that no low $\theta$ young worker will prefer risky search.

The boundary between Regime I and the ensuring Regime II is marked by a wage employment demand shifter $a_{W}$ just high enough for the first young low $\theta$ worker becomes indifferent between risky search and safe search.

\section{Regime II: All Young High $\theta$ Workers and Some Young Low $\theta$ Workers Adopt Risky Search}

A regime II equilibrium occurs when all young high $\theta$ workers plus some young low $\theta$ workers adopt risky search, while the rest of the young workers and all adult workers adopt safe search. In such an 
equilibrium, for a young low $\theta$ worker, the expected value of risky search $v_{r}(\pi, \theta)$ is equal to the expected value of safe search $v_{S}(\pi)$; this condition is analyzed further below. Meanwhile, for an adult worker, the expected value of risky search must be less than the expected value of safe search. Thus, $\max \left\{V_{r}(\pi), V_{S}\right\}=V_{S}=w_{F}$.

Further analyzing the condition for young workers, it follows that for all low $\theta$ young workers that is, those for whom $\theta<\hat{\theta}=0$-- we have that,

$$
\begin{aligned}
& v_{r}(\pi, \tilde{\theta})=v_{s}(\pi) \\
& \Leftrightarrow \pi\left[w_{W}(1+\rho)\right]+(1-\pi) \rho \max \left\{V_{r}(\pi), V_{s}\right\}=w_{F}+\rho \max \left\{V_{r}(\pi), V_{s}\right\} \\
& \Leftrightarrow \pi\left[w_{W}(1+\rho)\right]+(1-\pi) \rho w_{F}=w_{F}+\rho w_{F} \\
& \Leftrightarrow \pi\left[w_{W}(1+\rho)-\rho w_{F}\right]=w_{F} \\
& \Leftrightarrow \pi=\frac{w_{F}}{w_{W}+\rho\left(w_{W}-w_{F}\right)}=\hat{\pi} .
\end{aligned}
$$

Equation (15) shows that for a young low $\theta$ worker to be indifferent between the two search options, the wage employment likelihood must be exactly equal to $\hat{\pi}$ as shown. Note that the free entry wage, the wage employment wage, and the discount factor all play a role in the determination of this threshold wage employment probability. In particular, when faced with a higher free entry wage, a lower wage employment wage, or a lower discount factor, a higher wage employment likelihood will be required if a low $\theta$ young worker is to continue to remain indifferent between the two search options. This will happen provided that there are few enough job openings in wage employment so that young low $\theta$ workers are able to allocate themselves among search strategies in order to equalize the expected values associated with the two of them.

Now, from (4), the probability of wage employment is also given by the ratio:

$$
\pi=\frac{\text { job openings in wage employment }}{\text { total number of risky job seekers }} \text {. }
$$

In regime II where all $\mathcal{L} / 2$ young high $\theta$ workers adopt risky search with the intention of leaving wage employment to enter high-paying self-employment after one period of wage employment and where all $\mathcal{L} / 2$ young low $\theta$ workers who adopt risky search enter wage employment with the intention of staying two periods, the number of wage employment stayers is equal to the total number of low $\theta$ workers in wage employment. With $\mathcal{J}_{r}$ being the total number of risky job seekers, the number of low $\theta$ risky job seekers is $\mathcal{J}_{r}-\mathcal{L} / 2$. A fraction $\pi$ of these will obtain wage employment when young and will remain in wage employment as adults. It follows that job openings in wage employment will arise for two reasons - to replace older workers who retire and to replace young high $\theta$ workers who start in high-wage employment and move to self-employment - in which case: 


$$
\text { job openings in wage employment }=\mathcal{E}_{W}-\pi\left(\mathcal{J}_{r}-\mathcal{L} / 2\right) .
$$

Taking the ratio of job openings in wage employment as given by (16) to the total number of risky job seekers gives the following value of $\pi$ :

$$
\pi=\frac{\mathcal{E}_{W}-\pi\left(\mathcal{J}_{r}-\mathcal{L} / 2\right)}{\mathcal{J}_{r}}
$$

Equations (15) and (17) are a pair of simultaneous equations in two unknowns $\mathcal{J}_{r}$ and $\pi$. Solving, we obtain the equilibrium number of job seekers $\mathcal{J}_{r}^{*}$ in regime II:

$$
\mathcal{J}_{r}^{*}=\frac{1}{2}\left(\frac{\mathcal{E}_{W}}{\pi^{*}}+\frac{\mathcal{L}}{2}\right)=\frac{1}{2}\left(\frac{\mathcal{E}_{W}\left(w_{W}(1+\rho)-\rho w_{F}\right)}{w_{F}}+\frac{\mathcal{L}}{2}\right) .
$$

From (15), the corresponding equilibrium wage employment probability in regime II is:

$$
\pi=\frac{w_{F}}{w_{W}+\rho\left(w_{W}-w_{F}\right)}=\hat{\pi} .
$$

To recall, $\hat{\pi}$ is the largest value of $\pi$ consistent with a regime I equilibrium for the last indifferent risky job seeker with $\tilde{\theta}=\hat{\theta}=0$. Equations (18) and (19) are respectively the closed form solutions for the number of risky job seekers and the corresponding wage employment likelihood in regime 2 . To check that the equilibrium displayed in (18) and (19) is one where all young high $\theta$ workers plus some low $\theta$ workers adopt risky search, it remains to be shown that $\mathcal{J}_{r}^{*}$ in (18) is indeed greater than the number of young high $\theta$ workers $\mathcal{L} / 2$, but less than the total number of young workers $\mathcal{L}$, or equivalently using the expression for $\mathcal{J}_{r}^{*}$ in (18),

$$
\frac{\mathcal{L}}{2} \leq \mathcal{J}_{r}^{*}<\mathcal{L} \Leftrightarrow \frac{\hat{\pi}}{2} \leq \frac{\mathcal{E}_{W}}{\mathcal{L}}<\frac{3 \hat{\pi}}{2}
$$

The condition in (20) requires that in a regime II equilibrium, the number of jobs in wage employment must be strictly higher than that which prevails in a regime I equilibrium $\left(\mathcal{E}_{W} / \mathcal{L}>\hat{\pi} / 2\right)$, but not too high $\left(\varepsilon_{W} / \mathcal{L}<3 \hat{\pi} / 2\right)$, so that adult workers continue to prefer the safe search strategy.

Comparing the regime I condition (14) with the regime II condition (20), it is easy to see that regime I and regime II equilibria are mutually exclusive, in the sense that if the condition guaranteeing regime I equilibrium holds $\left(\mathcal{E}_{W} / \mathcal{L}<\hat{\pi} / 2\right)$, then the condition guaranteeing a regime II equilibrium $\left(\hat{\pi} / 2<\mathcal{E}_{W} / \mathcal{L}<3 \hat{\pi} / 2\right)$ must be violated, and vice versa. It follows that multiple equilibria involving both regimes I and II cannot exist.

Regime II ends when all young workers adopt risky search but no other workers do. 


\section{Regime III: All Young Workers and No Adult workers Adopt Risky Search}

A regime III equilibrium occurs when all young workers adopt risky search, while all adult workers adopt safe search. In this equilibrium it must first of all be the case that the expected values of risky search among high and low $\theta$ young workers are higher than their respective expected values of safe search. As shown in section 2, the expected value gains from risky search among young high $\theta$ workers are never lower than those of young low $\theta$ workers, and so it suffices to require the expected value of risky search among young low $\theta$ workers to be higher than the expected value of safe search. Equivalently, using (6) and (7) for young workers whose $\theta s$ are less than the critical value $\hat{\theta}$,

$$
\begin{aligned}
& v_{r}(\pi, \theta) \geq v_{s}(\pi) \\
& \Leftrightarrow \pi\left[w_{W}(1+\rho)\right]+(1-\pi) \rho \max \left\{V_{r}(\pi), V_{s}\right\} \geq w_{F}+\rho \max \left\{V_{r}(\pi), V_{s}\right\} \\
& \Leftrightarrow \pi\left[w_{W}(1+\rho)\right]+(1-\pi) \rho w_{F} \geq w_{F}+\rho w_{F} \\
& \Leftrightarrow \pi\left[w_{W}(1+\rho)-\rho w_{F}\right] \geq w_{F} \\
& \Leftrightarrow \pi \geq \pi .
\end{aligned}
$$

Since no adults adopt risky search in this regime, it must also be the case that the expected value of risky search of an adult worker is less than his expected value of safe search $V_{r}(\pi)=\pi w_{W}<V_{S}=w_{F}$ :

$$
V_{r}(\pi)<V_{S} \Leftrightarrow \pi<\frac{w_{F}}{w_{W}}
$$

Henceforth, we will denote the right hand side of (22) above as

$$
\frac{w_{F}}{w_{W}} \equiv \bar{\pi}
$$

and understand $\bar{\pi}$ as the wage employment probability that renders an adult worker indifferent between the safe and risky search strategies in regime III.

Since

$$
\hat{\pi} \equiv \frac{w_{F}}{w_{W}(1+\rho)-\rho w_{F}}
$$

and given that a maintained assumption of the model is that $w_{W}>w_{F}$, it follows that $\hat{\pi}$ is less than $\bar{\pi}$. For a range of values of $\pi \in[\widehat{\pi}, \bar{\pi}),(21)$ and (22) together imply that all $\mathcal{L}$ young workers adopt risky search, while all $\mathcal{L}$ adult workers choose the safe search strategy.

Within this range, the exact equilibrium probability of wage employment that applies can be determined by once again referring to (4), where:

$$
\pi=\frac{\text { job openings in wage employment }}{\text { total number of risky job seekers }} \text {. }
$$


In regime III where all young workers adopt risky search and no adult workers do, the total number of wage employment stayers is equal to the total number of low $\theta$ workers in wage employment, or $\pi$ times half of the total young work force $\mathcal{L} / 2$. It follows that:

$$
\text { job openings in wage employment }=\mathcal{E}_{W}-\pi \mathcal{L} / 2 \text {. }
$$

Taking the ratio of (23) to total number of risky job seekers, we obtain:

$$
\pi=\frac{\mathcal{E}_{W}-\pi \mathcal{L} / 2}{J_{r}}
$$

In a regime III equilibrium where the total number of risky job seekers is equal to the total number of young workers $\mathcal{L}$ :

$$
\mathcal{J}_{r}^{*}=\mathcal{L} .
$$

Substituting the above into (24), the equilibrium wage employment probability in regime III is thus

$$
\pi^{*}=\frac{2 \varepsilon_{W}}{3 \mathcal{L}} .
$$

Equations (25) and (26) are the closed form solutions for the number of risky job seekers and the wage employment probability in a regime III equilibrium. Equation (26), in particular, can be used to check that the equilibrium wage employment probability $\pi^{*}$ indeed lies in the range $(\hat{\pi}, \bar{\pi})$ required for a regime III equilibrium,

$$
\hat{\pi} \leq \pi^{*}<\bar{\pi} \Leftrightarrow \frac{3 \hat{\pi}}{2} \leq \frac{\mathcal{E}_{W}}{\mathcal{L}}<\frac{3 \bar{\pi}}{2}
$$

or equivalently,

$$
\frac{3 w_{F}}{2\left(w_{W}(1+\rho)-\rho w_{F}\right)} \leq \frac{\varepsilon_{W}}{\mathcal{L}}<\frac{3 w_{F}}{2 w_{W}} .
$$

The first inequality on the right hand side of (27) requires that the number of jobs in wage employment be higher than the number in a regime II equilibrium $\left(\mathcal{E}_{W} / \mathcal{L} \geq 3 w_{F} /\left(2\left(w_{W}(1+\rho)-\rho w_{F}\right)\right)\right)$. The second inequality on the right hand side of (27) requires, by contrast, that the number of jobs in wage employment not be so high as to encourage adult workers to engage in risky search, which is the case if $\varepsilon_{W} / \mathcal{L}<3 w_{F} /\left(2 w_{W}\right){ }^{4}$

$$
\text { Comparing } \varepsilon_{W} / \mathcal{L}<\hat{\pi} / 2 \text { in (14), } \hat{\pi} / 2 \leq \mathcal{E}_{W} / \mathcal{L}<3 \hat{\pi} / 2 \text { in (20), and } 3 \hat{\pi} / 2 \leq \mathcal{E}_{W} / \mathcal{L}<3 \bar{\pi} / 2 \text { in }
$$

(27), it is straightforward to see that multiple labor market equilibria involving more than one of the three regimes (I, II and III) is an impossibility.

\footnotetext{
${ }^{4}$ This follows from (22), which shows that if the equilibrium wage employment probability $\pi^{*}$ exceeds $\bar{\pi}$, then adult workers strictly prefer risky search, and from (26), which shows that the equilibrium wage employment probability indeed exceeds $\hat{\pi}=w_{F} /\left(w_{W}(1+\rho)-\rho w_{F}\right)$ if and only if $\mathcal{E}_{W} / \mathcal{L}>3 \bar{\pi} / 2=3 w_{F} /\left(2 w_{W}\right)$.
} 


\section{Regime IV: All Young Workers and Some Adult Workers Adopt Risky Search}

A regime IV equilibrium occurs when all young workers plus some adult workers adopt risky search. In such an equilibrium, the expected value of risky search for an adult worker is equal to the expected value of safe search. Thus,

$$
V_{r}(\pi)=V_{s} \Leftrightarrow \pi=\frac{w_{F}}{w_{W}}=\bar{\pi} .
$$

Equation (28) shows that for an adult worker to be indifferent between risky and safe search, the wage employment likelihood must be exactly equal to $\bar{\pi}$ as shown. Note that the ratio of the free entry wage and the wage employment wage completely determines this threshold wage employment probability. Thus, a higher free entry wage or a lower wage employment wage will result in an increase in the equilibrium likelihood that the risky search strategy will prove successful, the magnitude of the increase being just enough that an adult worker remains indifferent between risky search as compared with safe search. Unlike (15), which pertains to the choice of search strategy for young low $\theta$ workers, the discount factor $\rho$ plays no role in the choice of search strategy for adult workers, who have only one period of working life remaining.

From (4), the wage employment probability is given by the ratio:

$$
\pi=\frac{\text { job openings in wage employment }}{\text { total number of risky job seekers }}
$$

To determine the number of job openings in wage employment, note that in regime IV there are three types of workers in wage employment in every period: young high $\theta$ workers who leave after one period to enter high-paying self-employment, young low $\theta$ workers who stay in wage employment for two periods, and adult workers who retire after one period. The numbers of workers in these three groups are respectively $\pi \mathcal{L} / 2, \pi \mathcal{L} / 2$, and $\pi\left(\mathcal{J}_{r}-\mathcal{L}\right)$ adult workers who retire after one period. It follows that the total number of wage employment stayers is simply given by the number of low $\theta$ young workers in wage employment, $\pi \mathcal{L} / 2$, and thus:

$$
\text { job openings in wage employment }=\mathcal{E}_{W}-\pi \mathcal{L} / 2 \text {. }
$$

$\pi$, the probability of wage employment, is therefore:

$$
\pi=\frac{\mathcal{E}_{W}-\pi \mathcal{L} / 2}{\mathcal{J}_{r}} .
$$

Combining (28) and (30), we obtain the equilibrium number of risky job seekers in regime IV as

$$
\mathcal{J}_{r}^{*}=\frac{\mathcal{E}_{W}}{\pi^{*}}-\frac{\mathcal{L}}{2}=\frac{\mathcal{E}_{W} w_{W}}{w_{F}}-\frac{\mathcal{L}}{2}
$$

and the corresponding wage employment probability as 


$$
\pi^{*}=\frac{w_{F}}{w_{W}}=\bar{\pi}
$$

To check that the labor market equilibrium depicted in (31) and (32) is indeed consistent with regime IV, we verify that the number of risky job seekers is indeed greater than $\mathcal{L}$, the number of young workers in a generation, but less than the total possible number of job seekers in a steady state $\mathcal{L}+\left(1-\pi^{*}\right) \mathcal{L}$, which includes $\mathcal{L}$ young workers, and $\left(1-\pi^{*}\right) \mathcal{L}$ adult workers who must continue to search since they fail to find wage employment while a young worker. Thus, using the expression for $\mathcal{J}_{r}^{*}$ in (31):

$$
\mathcal{L} \leq \mathcal{J}_{r}^{*}<\left(2-\pi^{*}\right) \mathcal{L} \Leftrightarrow \frac{3 \bar{\pi}}{2} \leq \frac{\mathcal{E}_{W}}{\mathcal{L}}<\bar{\pi}\left(\frac{5}{2}-\bar{\pi}\right) .
$$

Note that the range displayed in (33) above, $(3 \bar{\pi} / 2, \bar{\pi}(5 / 2-\bar{\pi}))$, is non-empty since $\bar{\pi}(5 / 2-\bar{\pi})-$ $3 \bar{\pi} / 2=\bar{\pi}(1-\bar{\pi})>0$. The right hand side of (33) requires that wage employment demand be higher than that of a regime III equilibrium $\left(\mathcal{E}_{W} / \mathcal{L} \geq 3 \bar{\pi} / 2\right)$, but not so high that all adult workers prefer safe $\operatorname{search}\left(\varepsilon_{W} / \mathcal{L}<\bar{\pi}(5 / 2-\bar{\pi})\right)$.

$$
\text { From } \varepsilon_{W} / \mathcal{L}<\hat{\pi} / 2 \text { in (14), } \hat{\pi} / 2 \leq \mathcal{E}_{W} / \mathcal{L}<3 \hat{\pi} / 2 \text { in (20), } 3 \hat{\pi} / 2 \leq \mathcal{E}_{W} / \mathcal{L}<3 \bar{\pi} / 2 \text { in (27), and }
$$

$3 \bar{\pi} / 2 \leq \mathcal{E}_{W} / \mathcal{L}<\bar{\pi}(5 / 2-\bar{\pi})$ in (33) above, it can be verified that multiple equilibria involving more than one of the four regimes discussed so far are not possible.

\section{Regime V: All Adopt Risky Search}

In this final regime, all workers, young and adult, adopt risky search. In an equilibrium in this regime, the expected value of risky search of an adult worker is strictly greater than the expected value of safe search, i.e.,

$$
V_{r}(\pi) \geq V_{s} \Leftrightarrow \pi \geq \frac{w_{F}}{w_{W}}=\bar{\pi}
$$

Furthermore, in such an equilibrium, the total number of risky job seekers is equal to

$$
\mathcal{J}_{r}=(2-\pi) \mathcal{L}
$$

as discussed before. Of these risky job seekers, $\mathcal{L} / 2$ are young high $\theta$ workers, $\mathcal{L} / 2$ are young low $\theta$ workers, and $(1-\pi) \mathcal{L}$ are adult workers who failed to find wage employment while young. It follows that the number of wage employment stayers in this regime is equal to $\pi$ times the number of young low $\theta$ risky job seekers, or $\pi \mathcal{L} / 2$. In regime $V$, therefore: 


$$
\text { job openings in wage employment }=\mathcal{E}_{W}-\pi \mathcal{L} / 2 \text {. }
$$

Taking the ratio of job openings in wage employment to risky job seekers, the probability of wage employment, from (4), is:

$$
\pi=\frac{\varepsilon_{W}-\pi \mathcal{L} / 2}{\text { total number of risky job seekers }} .
$$

Equations (35) and (37) are a pair of simultaneous equations in two unknowns, $\mathcal{J}_{r}$ and $\pi$. Solving, we obtain:

$$
0=\left(\pi^{*}\right)^{2}-\frac{5}{2} \pi^{*}+\frac{\mathcal{E}_{W}}{\mathcal{L}}
$$

which is a quadratic equation in $\pi^{*}$. The two roots are given by

$$
\frac{5}{4} \pm \sqrt{\left(\frac{5}{4}\right)^{2}-\frac{\mathcal{E}_{W}}{\mathcal{L}}}
$$

Picking the root that does not exceed unity, the equilibrium wage employment probability and the number of risky job seekers are

$$
\pi^{*}=\frac{5}{4}-\sqrt{\left(\frac{5}{4}\right)^{2}-\frac{\mathcal{E}_{W}}{\mathcal{L}}}
$$

and

$$
\mathcal{J}_{r}^{*}=\frac{3 \mathcal{L}}{4}+\sqrt{\left(\frac{5 \mathcal{L}}{4}\right)^{2}-\mathcal{E}_{W} \mathcal{L}}
$$

A labor market equilibrium like (38) - (39) is consistent with regime $V$ if and only if all young and adult workers strictly prefer risky search. From (34), this requires that $\pi^{*}>\bar{\pi}$. Furthermore, the equilibrium wage employment probability does not exceed unity if and only if $1 \geq \pi^{*}$. Taken together, the conditions guaranteeing a regime $V$ equilibrium are:

$$
1 \geq \frac{5}{4}-\sqrt{\left(\frac{5}{4}\right)^{2}-\frac{\mathcal{E}_{W}}{\mathcal{L}}} \geq \bar{\pi} \Leftrightarrow \bar{\pi}\left(\frac{5}{2}-\bar{\pi}\right) \leq \frac{\mathcal{E}_{W}}{\mathcal{L}} \leq \frac{3}{2} .
$$

From the left inequality on the right hand side of (40), wage employment demand needs to be higher than what is required for Regime IV $\left(\varepsilon_{W} / \mathcal{L}>\bar{\pi}(5 / 2-\bar{\pi})\right)$. As for the right inequality on the right hand side of (40), suppose that there is indeed a ratio of three wage jobs to every two workers in a generation. With this many wage jobs, all $\mathcal{L}$ young workers, plus half of all adult workers is just enough 
to satisfy wage employment demand $\varepsilon_{W}$. The other half of the adult work force is engaged in highpaying self-employment, after having spent one period as a wage employee. The implied likelihood of wage employment given $\mathcal{L} / 2$ wage employment stayers each period, and $\mathcal{L}$ job seekers (all young) is exactly equal to unity. ${ }^{5}$

Finally, from (14), (20), (27), (33), and (40) above, we get the following jointly exhaustive and mutually exclusive boundaries for $\mathcal{E}_{W} / \mathcal{L}$ corresponding to each regime

$$
\left\{\begin{array}{l}
\text { Regime I } \quad \text { if } \frac{\mathcal{E}_{W}}{\mathcal{L}} \in\left(0, \frac{\hat{\pi}}{2}\right) \\
\text { Regime II } \quad \text { if } \frac{\mathcal{E}_{W}}{\mathcal{L}} \in\left[\frac{\hat{\pi}}{2}, \frac{3 \hat{\pi}}{2}\right) \\
\text { Regime III } \quad \text { if } \frac{\mathcal{E}_{W}}{\mathcal{L}} \in\left[\frac{3 \hat{\pi}}{2}, \frac{3 \bar{\pi}}{2}\right) \\
\text { Regime IV } \\
\text { Regime } V \quad \text { if } \frac{\mathcal{E}_{W}}{\mathcal{L}} \in\left[\frac{3 \bar{\pi}}{2}, \bar{\pi}\left(\frac{5}{2}-\bar{\pi}\right)\right]
\end{array}\right.
$$

\section{Comparative Statics:}

In this section, we present the comparative statics properties of the labor market equilibrium with respect to different values of wage employment demand across the five regimes of interest. To flesh out intuitions, we will begin by examining the relationship between wage employment demand and the ex ante allocation of labor into risky search on the part of young and adult workers, $\mathcal{J}_{r}^{*}$. Later in this section, we will turn next to ex post labor allocation of young and adult workers among (i) unemployment, (ii) wage employment, (iii) high-paying self-employment, and (iv) free entry selfemployment in the five successive regimes.

\subsection{Ex-Ante Labor Allocation: $\mathcal{J}_{r}^{*}$}

Collecting results from (12), (18), (25), (31) and (39), the total number of workers adopting risky search in the five regimes of interest, normalized by the size of the total workforce in each generation, is summarized in Table 1.

\footnotetext{
${ }^{5}$ For $\mathcal{E}_{W} / \mathcal{L}$ greater than $3 / 2$, the corner solution $\mathcal{J}_{r}^{*}=1$ applies, and the equilibrium likelihood of wage employment is equal to 1 .
} 
Of these risky job seekers, all $\mathcal{J}_{\mathrm{r}}^{*}$ of them are young workers in regimes I $-\mathrm{III}$, i.e., $j_{r}^{*}=\mathcal{J}_{r}^{*}$, since only young workers adopt risky search in these first three regimes. In regimes IV and V, all young workers adopt risky search, i.e., $j_{r}^{*}=\mathcal{L}$. The normalized number of young risky job seekers across the five regimes is:

$$
\frac{j_{r}^{*}}{\mathcal{L}}= \begin{cases}\frac{\mathcal{E}_{W}}{\mathcal{L}} \frac{w_{W}+\rho\left(w_{W}+\bar{\theta}-w_{F}\right)}{\left(w_{F}+\frac{2 \rho \bar{\theta} \varepsilon_{W}}{\mathcal{L}}\right)} & \text { if } \frac{\mathcal{E}_{W}}{\mathcal{L}} \text { in Reg.I } \\ \frac{1}{2}\left(\frac{1}{\hat{\pi}} \frac{\mathcal{E}_{W}}{\mathcal{L}}+\frac{1}{2}\right) & \text { if } \frac{\mathcal{E}_{W}}{\mathcal{L}} \text { in Reg.II } \\ 1 & \text { if } \frac{\mathcal{E}_{W}}{\mathcal{L}} \text { in Reg.III }\end{cases}
$$

The corresponding number of adult risky job seekers is given by $J_{r}^{*}=\mathcal{J}_{r}^{*}-j_{r}^{*}$, or from Table 1 and (41),

$$
\frac{J_{r}^{*}}{\mathcal{L}}= \begin{cases}\frac{1}{\bar{\pi}} \frac{\mathcal{E}_{W}}{\mathcal{L}}-\frac{3}{2} & \text { if } \frac{\mathcal{E}_{W}}{\mathcal{L}} \text { in Reg.I,II or III } \\ -\frac{1}{4}+\sqrt{\left(\frac{5}{4}\right)^{2}-\frac{\mathcal{E}_{W}}{\mathcal{L}}} & \text { if } \frac{\mathcal{E}_{W}}{\mathcal{L}} \text { in Reg.IV } \\ \text { if } \frac{\mathcal{E}_{W}}{\mathcal{L}} \text { in Reg.V }\end{cases}
$$

Figure 1 plots $\mathcal{J}_{r}^{*} / \mathcal{L}, j_{r}^{*} / \mathcal{L}$ and $J_{r}^{*} / \mathcal{L}$ as shown above as functions of wage employment demand $\mathcal{E}_{W} / \mathcal{L}$, all else constant including wages $w_{W}$ and $w_{F}$, the discount factor $\rho$, and the range of $\theta$ assuming a uniform distribution on $[-\bar{\theta}, \bar{\theta}$,$] . Thus, going from left to right, \varepsilon_{W} / \mathcal{L}$ rises from the lowest possible value (0) to the highest possible value (3/2). The five ranges of $\varepsilon_{W} / \mathcal{L}$ consistent with regimes I- $\mathrm{V}$ are also shown along the horizontal axis.

As displayed, $\mathcal{J}_{r}^{*}$ as a function of $\mathcal{E}_{W} / \mathcal{L}$ has a complicated shape: it increases strictly in regimes I and II, remains unchanged in regime III, increases strictly in regime IV, and strictly decreases in regime V. The intuition is as follows. For $\mathcal{E}_{W} / \mathcal{L}$ sufficiently low in regimes I - IV, an increase in wage employment demand encourages risk taking, first by young high $\theta$ workers (regime I), followed by young low $\theta$ workers (regimes II and III), and lastly by adult workers (regime IV). Regime V, in sharp contrast with all the other regimes, is one where all job seekers including youth and adults already participate in risky search. Raising wage employment demand even further raises the number of young workers who successfully achieve wage employment while young, thereby decreasing the number of remaining persons left to engage in risky search as adults. It is for this reason that $\mathcal{J}_{r}^{*}$ in regime $\mathrm{V}$ is in fact strictly decreasing in wage employment demand, as depicted. 


\subsection{Ex-Post Allocation among Labor Market Outcomes}

\section{Unemployment}

Unemployment as an ex-post labor market outcome arises whenever some worker engages in risky search and fails to find wage employment. The likelihood of this event facing a risky job seeker is $1-\pi^{*}$. With the total number of risky job seekers being given by $\mathcal{J}_{r}^{*}$, total unemployment $\mathcal{U}^{*}=u^{*}+U^{*}$ is equal to $\left(1-\pi^{*}\right) \mathcal{J}_{r}^{*}$. Making use of (13), (15), (26), (32), (38) and (41), Table 1 shows the equilibrium level of total unemployment normalized by the size of the total workforce. Among the $\mathcal{U}^{*}$ unemployed workers, total youth unemployment is $1-\pi^{*}$ times the number of risky young job seekers. Since only young workers engage in risky search in regimes I - III, $u^{*}=\left(1-\pi^{*}\right) j_{r}^{*}=\left(1-\pi^{*}\right) \mathcal{J}_{r}^{*}$. In regimes IV and $\mathrm{V}$, all young workers engage in risky search; it follows that $u^{*}=\left(1-\pi^{*}\right) \mathcal{L}$ in those regimes. Thus, collecting results from section 3 for each of the five regimes on $\pi^{*}$ and $\mathcal{J}_{r}^{*}$, the fraction of youth who are unemployed is given by:

$$
\frac{u^{*}}{\mathcal{L}}= \begin{cases}\frac{\mathcal{E}_{W}}{\mathcal{L}} \frac{w_{W}+\rho\left(w_{W}+\bar{\theta}-w_{F}\right)}{\left(w_{F}+\frac{2 \bar{\theta} \rho \mathcal{E}_{W}}{\mathcal{L}}\right)}-\frac{\mathcal{E}_{W}}{\mathcal{L}} & \text { if } \frac{\mathcal{E}_{W}}{\mathcal{L}} \text { in Reg.I } \\ \frac{1-\hat{\pi}}{2}\left(\frac{1}{\hat{\pi}} \frac{\mathcal{E}_{W}}{\mathcal{L}}+\frac{1}{2}\right) & \text { if } \frac{\mathcal{E}_{W}}{\mathcal{L}} \text { in Reg.II } \\ \left(1-\frac{2}{3} \frac{\mathcal{E}_{W}}{\mathcal{L}}\right) & \text { if } \frac{\mathcal{E}_{W}}{\mathcal{L}} \text { in Reg.III } \\ (1-\bar{\pi}) & \text { if } \frac{\mathcal{E}_{W}}{\mathcal{L}} \text { in Reg.IV } \\ \left(-\frac{1}{4}+\sqrt{\left.\left(\frac{5}{4}\right)^{2}-\frac{\mathcal{E}_{W}}{\mathcal{L}}\right)}\right. & \text { if } \frac{\mathcal{E}_{W}}{\mathcal{L}} \text { in Reg.V }\end{cases}
$$

Meanwhile, total adult unemployment is given by $U^{*}=\mathcal{U}^{*}-u^{*}$, or

$$
\frac{U^{*}}{\mathcal{L}}=\left\{\begin{array}{lr}
0 & \text { if } \frac{\mathcal{E}_{W}}{\mathcal{L}} \text { in Reg.I,II or III } \\
(1-\bar{\pi})\left(\frac{1}{\bar{\pi}} \frac{\mathcal{E}_{W}}{\mathcal{L}}-\frac{3}{2}\right) & \text { if } \frac{\mathcal{E}_{W}}{\mathcal{L}} \text { in Reg.IV } \\
\left(-\frac{1}{4}+\sqrt{\left.\left(\frac{5}{4}\right)^{2}-\frac{\mathcal{E}_{W}}{\mathcal{L}}\right)^{2}}\right. & \text { if } \frac{\mathcal{E}_{W}}{\mathcal{L}} \text { in Reg.V }
\end{array}\right.
$$

Figures $2 \mathrm{a}$ and $2 \mathrm{~b}$ illustrate total unemployment, youth unemployment, and adult unemployment as functions of wage employment demand $\varepsilon_{W} / \mathcal{L}$. In Figure $2 \mathrm{a}$, the spread of $\theta$ is assumed to be 
sufficiently small, while in Figure $2 b$, a sufficiently larger spread is assumed. ${ }^{6}$ Focusing first on Figure $2 a$, total unemployment $\mathcal{U}^{*}$ is twin-peaked -- strictly increasing in regimes I and II, strictly decreasing in regime III, strictly increasing again in regime IV, finally decreasing to zero in regime $\mathrm{V}$. The intuition behind the non-monotonicity of $\mathcal{U}$ with respect to $\mathcal{E}_{W} / \mathcal{L}$ is as follows. In regimes I and II, where only young workers are risky job seekers, an increase in wage employment demand $\Delta \mathcal{E}_{W}$ encourages more than $\Delta \mathcal{E}_{W}$ young workers to engage in risky job search, thereby adding to youth unemployment. ${ }^{7}$ Up to this point, adult workers do not engage in risky search, and as such adult unemployment is equal to zero.

As $\mathcal{E}_{W}$ rises even further, regime III now applies, where all young workers and no adult workers adopt risky search. Raising wage employment demand in the interior of this regime increases the number of wage employment jobs, while the number of risky job seekers remains constant at $\mathcal{L}$ in this regime. According to (26), an increase in $\mathcal{E}_{W}$ thus serves to raise the likelihood of wage employment, $\pi^{*}$. Consequently, youth unemployment falls, adult unemployment remains at zero, and thus total unemployment strictly decreases within regime III.

${ }^{6}$ Specifically, differentiate (44) evaluated at the interior of regime I to yield
\[ \frac{1}{\mathcal{L}} \frac{\partial \mathcal{U}^{*}}{\partial \mathcal{E}_{W}}=\frac{1}{\mathcal{L}}\left(\frac{w_{F}\left(w_{W}(1+\rho)+\rho\left(\bar{\theta}-w_{F}\right)\right)}{\left(w_{F}+\frac{2 \bar{\theta} \rho \mathcal{E}_{W}}{\mathcal{L}}\right)^{2}}-1\right), \]

and

$$
\frac{1}{\mathcal{L}} \frac{\partial \mathcal{U}^{*}}{\partial \mathcal{E}_{W} \partial \mathcal{E}_{W}}=-\frac{1}{\mathcal{L}^{2}} \frac{4 \rho \bar{\theta} w_{F}\left(w_{F}(1+\rho)+\rho\left(\bar{\theta}-w_{F}\right)\right)}{\left(w_{F}+\frac{2 \bar{\theta} \rho \mathcal{E}_{W}}{\mathcal{L}}\right)^{3}}<0,
$$

thus $\mathcal{U}^{*}$ is a strictly concave function with respect to $\varepsilon_{W}$. Furthermore, evaluating the slope $\partial \mathcal{U}^{*} / \partial \mathcal{E}_{W}$ at $\varepsilon_{W}=0$,

$$
\frac{1}{\mathcal{L}} \frac{\partial \mathcal{U}^{*}}{\partial \varepsilon_{W}} \mid\left(\varepsilon_{W}=0\right)=\frac{1}{\mathcal{L}}\left(\frac{w_{W}(1+\rho)+\rho\left(\bar{\theta}-w_{F}\right)}{w_{F}}-1\right)>0 .
$$

Thus, $\mathcal{U}^{*}$ is strictly increasing in $\varepsilon_{W}$ evaluated at $\varepsilon_{W}=0$. Now, at the other boundary of regime I, where $\varepsilon_{W} / \mathcal{L}=$ $\hat{\pi} / 2$,

if and only if

$$
\frac{1}{\mathcal{L}} \frac{\partial \mathcal{U}^{*}}{\partial \mathcal{E}_{W}} \mid\left(\frac{\mathcal{E}_{W}}{\mathcal{L}}=\frac{\hat{\pi}}{2}\right)=\frac{1}{\mathcal{L}}\left(\frac{\left[w_{W}(1+\rho)-\rho w_{F}\right]^{2}}{w_{F}\left[w_{W}(1+\rho)+\rho\left(\bar{\theta}-w_{F}\right)\right]}-1\right) \geq(<) 0
$$

$$
\bar{\theta} \leq(>)\left[w_{W}(1+\rho)-\rho w_{F}\right]\left(w_{W}-w_{F}\right)(1+\rho) /\left(\rho w_{F}\right) .
$$

Collecting results, it follows that if $\bar{\theta}$ is sufficiently small, $\mathcal{U}^{*}$ is a strictly increasing an concave function of $\mathcal{E}_{W}$ in the interior of regime $\mathrm{I}$. Otherwise if $\bar{\theta}$ is sufficiently large, $\mathcal{U}^{*}$ is a concave function that first rises and than falls with $\varepsilon_{W}$.

${ }^{7}$ Footnote 9 provides a proof of this claim for regime I. In regime II

$$
\frac{1}{\mathcal{L}} \frac{\partial \mathcal{U}^{*}}{\partial \mathcal{E}_{W}}=\frac{1-\hat{\pi}}{2 \hat{\pi} \mathcal{L}}>0
$$


As wage employment demand rises further, we come to a point where we leave regime III and enter regime IV. Additional wage employment demand now induces adult workers to participate in risky search. In this regime, a given increase in wage employment demand $\Delta \varepsilon_{W}$ encourages risky search among adult workers by more than $\Delta \mathcal{E}_{W}$, raising adult unemployment. Meanwhile, youth unemployment remains unchanged at $(1-\bar{\pi}) \mathcal{L}$, since the increase in wage employment demand and adult risky search behavior balance out each other in such a way that the likelihood of wage employment is constant and equal to $\bar{\pi}$ in regime IV; see (32). Thus, total unemployment necessarily increases, giving rise to a second peak in total unemployment at the threshold wage employment demand between regimes IV and $V$ - that is, at $\mathcal{E}_{W} / \mathcal{L}=\bar{\pi}(5 / 2-\bar{\pi})$, when all adult and young workers are engaged in risky search. Thereafter, any further increase in wage employment demand produces a strict decline in total unemployment. The reasons are two-fold. First, with all job seekers already participating in risky search, raising wage employment raises the number of young workers that successfully achieve wage employment while young, but decreases the total number of remaining adults who can participate in risky search upon reaching adulthood. As shown in (41), the total number of risky job seekers $\mathcal{J}_{r}^{*}$ decreases with $\mathcal{E}_{W}$. Furthermore, from (38), the likelihood of wage employment $\pi^{*}$ rises with wage employment demand here. Taken together, total unemployment $\left(1-\pi^{*}\right) \mathcal{J}_{r}^{*}$ must be decreasing in wage employment demand here.

We turn now to Figure $2 b$. As discussed, the difference between Figures $2 a$ and $2 b$ is in the spread of $\theta$. In particular, still continuing with the maintained assumption that $\theta$ is distributed uniformly on $[-\bar{\theta}, \bar{\theta}]$ the larger is $\bar{\theta}$, the more spread out the distribution of the payoff $\theta$ to high-paying selfemployment in regime I. With a more spread out $\theta$ distribution, the same increase in wage employment demand draws in a proportionally smaller number of risky job seekers. ${ }^{8}$ Since unemployment is given by the total number of risky job seekers minus the number of available job openings $\mathcal{J}_{r}^{*}-\varepsilon_{W}$, unemployment can in fact decrease with $\varepsilon_{W} / \mathcal{L}$ in regime I if $\mathcal{J}_{r}^{*}$ does not rise fast enough with $\mathcal{E}_{W}$, as would be the case when the distribution of $\theta$ is sufficiently spread out. This is precisely the case that Figure $2 \mathrm{~b}$ illustrates. Interestingly, this implies that the $\mathcal{U}^{*}$ schedule is now triple-peaked. ${ }^{9}$

\footnotetext{
${ }^{8}$ To see this, differentiate $\mathcal{J}_{r}^{*}$ with respect to $\mathcal{E}_{W} / \mathcal{L}$ to obtain

$$
\frac{\operatorname{dlog} \mathcal{J}_{r}^{*}}{\operatorname{dlog}\left(\mathcal{E}_{W}\right)}=\frac{w_{F}}{\left(w_{F}+\frac{2 \bar{\theta} \rho \mathcal{E}_{W}}{\mathcal{L}}\right)}
$$

an expression that is strictly decreasing in $\bar{\theta}$.

${ }^{9}$ Footnote 9 demonstrates that $\mathcal{U}^{*}$ is inverted $U$ shaped with respect to $\mathcal{E}_{W} / \mathcal{L}$ in the interior of regime I when $\bar{\theta}$ is sufficiently large.
} 


\section{The Number Working in Wage Employment}

In all regimes analyzed here, the number of workers available in the economy is greater than the number demanded by employers. Therefore total wage employment is exactly equal to wage employment demand $\varepsilon_{W}$ in equilibrium.

The split of $\mathcal{E}_{W}$ between adult and young workers may be determined as follows. Starting with wage employment among young workers $e_{W}$, multiply the equilibrium likelihood of wage employment $\pi^{*}$ by the number of young risky job seekers $j_{r}^{*}$ in each of the five regimes to obtain:

$$
\frac{e_{W}^{*}}{\mathcal{L}}= \begin{cases}\frac{\mathcal{E}_{W}}{\mathcal{L}} & \text { if } \frac{\mathcal{E}_{W}}{\mathcal{L}} \text { in Reg.I } \\ \frac{\hat{\pi}}{2}\left(\frac{1}{\hat{\pi}} \frac{\mathcal{E}_{W}}{\mathcal{L}}+\frac{1}{2}\right) & \text { if } \frac{\mathcal{E}_{W}}{\mathcal{L}} \text { in Reg.II } \\ \frac{2}{3} \frac{\mathcal{E}_{W}}{\bar{L}} & \text { if } \frac{\mathcal{E}_{W}}{\mathcal{L}} \text { in Reg.III } \\ \left(\frac{5}{4}-\sqrt{\left.\left(\frac{5}{4}\right)^{2}-\frac{\mathcal{E}_{W}}{\mathcal{L}}\right)}\right. & \text { if } \frac{\mathcal{E}_{W}}{\mathcal{L}} \text { in Reg.IV } \\ \text { if } \frac{\mathcal{E}_{W}}{\mathcal{L}} \text { in Reg.V }\end{cases}
$$

As for adult workers, the total number of adult workers in wage employment is (i) the number of young workers who find wage employment as youth and stay in wage employment as adults, which they will do if and only if they have low $\theta$, plus (ii) the number of adults who seek and find wage employment. The number in group (i) equals the number of young low $\theta$ workers who engage in risky search multiplied by the probability of success $\pi^{*}$. In regime I, there are no low $\theta$ workers who engage in risky search, but from regimes II onwards, the total number of young low $\theta$ workers who engage in risky search is simply $j_{r}^{*}-L_{h i g h \theta}$, or, the total number of young risky job seekers net of the total number of high $\theta$ young workers. Summing (i) and (ii):

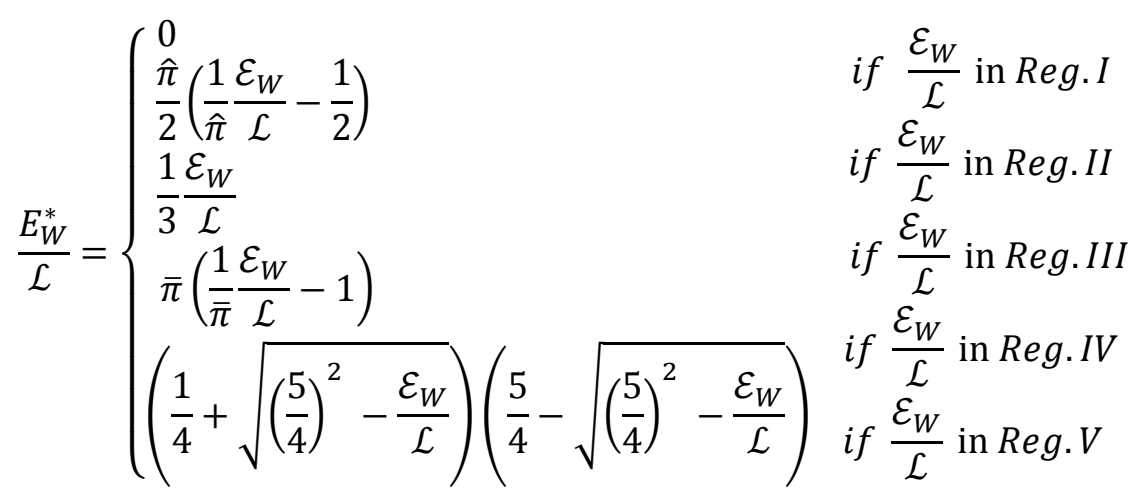


Figure 3 graphs youth wage employment $e_{W} / \mathcal{L}$, adult wage employment $E_{W} / \mathcal{L}$, and total wage employment $\mathcal{E}_{W} / \mathcal{L}$, each as a function of total wage employment $\mathcal{E}_{W} / \mathcal{L}$. As shown in Figure 3 , the youth wage employment function $e_{W} / \mathcal{L}$ is a strictly increasing function of the number of wage employment jobs in regimes I, II, and III, flat in regime IV, and again increasing in regime V. To recall, in regime IV, the probability of wage employment is constant at $\bar{\pi}$, while the total number of risky job seekers is likewise constant at $\mathcal{L}$ since all young workers engage in risky search in this regime. It follows that youth wage employment $-\bar{\pi}$ times $\mathcal{L}$-- must be independent of wage employment demand. We also see in Figure 3 the adult wage employment function $E_{W} / \mathcal{L}$. It is flat at zero in regime I because the only people who are hired into wage employment are high $\theta$ youth, all of whom move out of wage employment and into high-paying self-employment as adults. However, in regimes II, III and IV, some low $\theta$ persons are hired into wage employment as youth and choose to remain in wage employment as adults, and the number doing this increases with total wage employment. Finally in regime $\mathrm{V}$, where all adult workers not yet engaged in wage or high paying self-employment pursue risky search, adult wage

employment first rises and then falls with $\frac{\varepsilon_{W}}{\mathcal{L}}$, reflecting the balance between two separate effects of an increase in wage employment on adult wage employment. First, increasing wage employment increases the likelihood that an adult risky searcher finds wage employment. But going in the opposite direction, increasing wage employment also increases the number of high $\theta$ youths who will eventually engage in high paying self-employment by working in wage employment as youth. As such, the total number of remaining adult job seekers actually declines. The latter effect gets stronger as the total number of wage employment job rises. This inverted U-shaped relationship between wage employment demand and adult wage employment is shown in Figure 3.

Using (47) and (46), it can be easily verified that the sum of wage employment among adult and young workers, $E_{W}^{*}+e_{W}^{*}$, is indeed equal to $\varepsilon_{W}$. Furthermore, comparing $E_{W}^{*}$ and $e_{W}^{*}$, it is clear from Figure 3 that the total number of young workers in wage employment strictly exceeds the number of adults in wage employment. This corresponds well with our discussion in section 2.2 , reflecting therefore that young workers, with two rather than one period of work life remaining, have greater incentives than adult workers to participate in risky search, and thus attain wage employment.

\section{The Number Working in High-Paying Self-Employment}

High-paying self-employment in this economy $\mathcal{E}_{H}^{*}$ consists of workers who a) were in wage employment as youth, which enabled them to acquire the financial and human capital needed to enter self- 
employment, and who b) choose to enter self-employment because they can earn more there than they could in wage employment. Condition b) limits us to high $\theta$ individuals only. Thus $\mathcal{E}_{H}^{*}$ is given simply by $\pi^{*}$ times the total number of young high $\theta$ individuals who undertake risky search. In regime $\mathrm{I}$, the number of young high $\theta$ individuals who undertake risky search is equal to $\mathcal{J}_{r}^{*}$ itself. From regime II onwards, the total number of young high $\theta$ individuals who undertake risky search is equal to $L_{\text {high }} \theta=$ $\mathcal{L} / 2$. Thus, collecting results on $\pi^{*}$ and $\mathcal{J}_{r}^{*}$ from section 3 for each of the five regimes:

$$
\frac{\mathcal{E}_{H}^{*}}{\mathcal{L}}= \begin{cases}\frac{\mathcal{E}_{W}}{\mathcal{L}} & \text { if } \frac{\mathcal{E}_{W}}{\mathcal{L}} \text { in Reg.I } \\ \frac{\hat{\pi}}{2} \frac{\mathcal{E}_{W}}{\mathcal{L}} & \text { if } \frac{\mathcal{E}_{W}}{\mathcal{L}} \text { in Reg.II } \\ \frac{\bar{\pi}}{2} & \text { if } \frac{\mathcal{E}_{W}}{\mathcal{L}} \text { in Reg.III } \\ \frac{1}{2}\left(\frac{5}{4}-\sqrt{\left.\left(\frac{5}{4}\right)^{2}-\frac{\mathcal{E}_{W}}{\mathcal{L}}\right)}\right. & \text { if } \frac{\mathcal{E}_{W}}{\mathcal{L}} \text { in Reg. IV } \\ \text { if } \frac{\mathcal{E}_{W}}{\mathcal{L}} \text { in Reg. } V\end{cases}
$$

Since only adult workers can enter high-paying self-employment, $e_{H}^{*}=0$, and as such $\mathcal{E}_{H}^{*}=E_{H}^{*}$. Figure 4 plots high-paying self-employment as a function of wage employment demand $\varepsilon_{W} / \mathcal{L}$. As shown, highpaying self-employment is strictly increasing in wage employment demand in regimes I, III and V, and independent of wage employment demand in regimes II and IV. To see the intuition behind these variations in comparative statics responses, note first that in regime I, every wage employment job is occupied by a young high $\theta$ worker. It follows therefore that any increase in $\varepsilon_{W}$ will increase high-paying self-employment $\mathcal{E}_{H}^{*}$ one for one. Next, in regimes III and V, respectively all young workers, and all young and adult workers, are risky job seekers. Raising $\varepsilon_{W}$ here increases the likelihood of wage employment for all risky job seekers, including high $\theta$ young workers who plan to enter high-paying selfemployment as adults. It follows that raising $\mathcal{E}_{W}$ in these regimes increases high-paying self employment.

By contrast, in regimes II and IV, note from (19) and (32) that conditional on undertaking risky job search the likelihoods of wage employment are respectively constant at $\pi^{*}=\hat{\pi}$ and $\pi^{*}=\bar{\pi}$. It follows straightforwardly that increases in $\mathcal{E}_{W} / \mathcal{L}$ within these regimes will have no effect on the number of high-paying self-employed individuals since only high $\theta$ individuals enter high-paying selfemployment, and the number of such individuals is $\mathcal{L} / 2$, a constant in both regimes II and IV. 


\section{The Number Working in Free-Entry Self-Employment}

Free-entry self-employment is given by the number of job seekers who adopt the safe search strategy. Among young workers, this is simply given by $\mathcal{L}-j_{r}^{*}$. From (41),

$$
\frac{e_{F}^{*}}{\mathcal{L}}= \begin{cases}1-\frac{\mathcal{E}_{W}}{\mathcal{L}} \frac{w_{W}+\rho\left(w_{W}+\bar{\theta}-w_{F}\right)}{\left(w_{F}+\frac{2 \bar{\theta} \rho \mathcal{E}_{W}}{\mathcal{L}}\right)} & \text { if } \frac{\mathcal{E}_{W}}{\mathcal{L}} \text { in Reg.I } \\ 1-\frac{1}{2}\left(\frac{1}{\hat{\pi}} \frac{\mathcal{E}_{W}}{\mathcal{L}}+\frac{1}{2}\right) & \text { if } \frac{\mathcal{E}_{W}}{\mathcal{L}} \text { in Reg.II } \\ 0 & \text { if } \frac{\mathcal{E}_{W}}{\mathcal{L}} \text { in Reg.III }\end{cases}
$$

This relationship falls monotonically in regimes I and II, reaching zero at the end of regime II and remaining at zero thereafter. Turning to adult workers, there are two subgroups. The first adopted risky search while young but failed to gain wage employment; the number in this category is $\left(1-\pi^{*}\right) j_{r}^{*}$. The second chose safe search when young; their number is $\mathcal{L}-j_{r}^{*}$. The total number of adult job seekers is thus $\left(1-\pi^{*}\right) j_{r}^{*}+\mathcal{L}-j_{r}^{*}=\mathcal{L}-\pi^{*} j_{r}^{*}$. (The remaining adult workers are not job seekers because they have already found their best possible employment situation.) Of the $\mathcal{L}-\pi^{*} j_{r}^{*}$ adult job seekers, some $\left(J_{r}^{*}\right)$ choose risky search as adults, leaving $\mathcal{L}-\pi^{*} j_{r}^{*}-J_{r}^{*}$ as safe job searchers among adults. All of these safe job searchers end up in free-entry self-employment. We thus have:

$$
\frac{E_{F}^{*}}{\mathcal{L}}= \begin{cases}1-\frac{\mathcal{E}_{W}}{\mathcal{L}} & \text { if } \frac{\mathcal{E}_{W}}{\mathcal{L}} \text { in Reg.I } \\ 1-\frac{1}{2}\left(\frac{\mathcal{E}_{W}}{\mathcal{L}}+\frac{\hat{\pi}}{2}\right) & \text { if } \frac{\mathcal{E}_{W}}{\mathcal{L}} \text { in Reg.II } \\ 1-\frac{2}{3} \frac{\mathcal{E}_{W}}{\mathcal{L}} & \text { if } \frac{\mathcal{E}_{W}}{\mathcal{L}} \text { in Reg.III } \\ (2-\bar{\pi})-\left(\frac{1}{\bar{\pi}} \frac{\mathcal{E}_{W}}{\mathcal{L}}-\frac{1}{2}\right) & \text { if } \frac{\mathcal{E}_{W}}{\mathcal{L}} \text { in Reg.IV } \\ 0 & \text { if } \frac{\mathcal{E}_{W}}{\mathcal{L}} \text { in Reg.V }\end{cases}
$$

This number decreases monotonically in the first four regimes, reaching zero at the end of regime IV and remaining at zero in regime $\mathrm{V}$.

Summing adult and young workers in free-entry employment as given by (48) and (49), we have:

$$
\frac{\mathcal{E}_{F}^{*}}{\mathcal{L}}= \begin{cases}2-\frac{\mathcal{E}_{W}}{\mathcal{L}}-\frac{\mathcal{E}_{W}}{\mathcal{L}} \frac{w_{W}+\rho\left(w_{W}+\bar{\theta}-w_{F}\right)}{\left(w_{F}+\frac{2 \bar{\theta} \rho \mathcal{E}_{W}}{\mathcal{L}}\right)} & \text { if } \frac{\mathcal{E}_{W}}{\mathcal{L}} \text { in Reg.I } \\ 2-\frac{1+\hat{\pi}}{2 \hat{\pi}} \frac{\mathcal{E}_{W}}{\mathcal{L}}-\frac{1+\hat{\pi}}{4} & \text { if } \frac{\mathcal{E}_{W}}{\mathcal{L}} \text { in Reg.II } \\ 1-\frac{2}{3} \frac{\mathcal{E}_{W}}{\mathcal{L}} & \text { if } \frac{\mathcal{E}_{W}}{\mathcal{L}} \text { in Reg.III } \\ (2-\bar{\pi})-\left(\frac{1}{\bar{\pi}} \frac{\mathcal{E}_{W}}{\mathcal{L}}-\frac{1}{2}\right) & \text { if } \frac{\mathcal{E}_{W}}{\mathcal{L}} \text { in Reg.IV } \\ 0 & \text { if } \frac{\mathcal{E}_{W}}{\mathcal{L}} \text { in Reg.V }\end{cases}
$$


which is strictly decreasing with respect to $\mathcal{E}_{W} / \mathcal{L}$ In regimes I-IV before reaching zero and remaining at zero in regime $\mathrm{V}$. Figure 5 illustrates.

\subsection{Summary of the Effects of Increased Demand for Labor in Wage Employment}

What we found in this section is that as the amount of wage employment increases:

1. The number of risky job searchers increases in three of the regimes, is unchanged in one regime and falls in the fifth (Figure 1).

2. Unemployment changes non-monotonically, rising in some regimes and falling in others (Figures $2 a$ and $2 b)$.

3. More youth are drawn into wage employment, while adult wage employment first rises and then falls (Figure 3).

4. High-paying self-employment increases strictly in some regimes and is unchanged in others (Figure 4).

5. Free-entry self-employment decreases monotonically or is unchanged depending on the regime (Figure 5).

Table 2 summarizes these results in another way. The reader is invited to examine all of the changes within a given regime and/or how a given outcome variable changes from one regime to another.

\section{Conclusion}

This paper has incorporated three key heterogeneities into the standard Harris-Todaro labor market model: heterogeneity within self-employment, heterogeneity in ability, and heterogeneity in age. We have shown that these heterogeneities can be brought together in tractable fashion to characterize equilibrium in a model whose features comes closer to the realities of developing economies. The model has allowed us to ask questions which cannot be addressed in the standard model. Further, we have shown that key results of the standard model can be overturned.

We have shown that the model has five regimes, in which different combinations of young and old are undertaking the risky search strategy, viz., trying for a high-wage job and taking one up if successful, ending up unemployed if unsuccessful. The model yields these five distinct regimes depending on parameter values:

- Regime I: Risky search is undertaken only by some of the young workers who are of high enough entrepreneurial ability that they will begin in wage employment and then use 
the skills and experience gained in wage employment to enter high-paying selfemployment as adults;

- Regime II: Risky search is undertaken by all of the high-ability young workers as well as some of the other young workers, who do not have high enough entrepreneurial ability to enter self-employment, but for whom justification for participating in risky search is purely to find wage employment;

- Regime III: Risky search is undertaken by all young workers but no adult workers;

- Regime IV: Risky search is undertaken by all young workers and also by some adult workers who are not already in wage employment or in high-paying self-employment, for whom the justification for participating in risky search as an adult worker is to find wage employment as an adult.

- Regime V: Risky search is undertaken by all young workers, and by all adult workers not already in wage employment or high-paying self-employment.

Let us now answer the three questions posed at the start of this paper: Does increasing high-wage employment increase or decrease unemployment? What does increasing high-wage employment do to youth and adult unemployment? What does increasing high-wage employment do to high-paying selfemployed and low-wage free-entry work?

We start by considering what happens to the relevant labor market outcomes as wage employment increases. At very low levels of wage employment, the probability of getting a job is so low that it is not worth any adult worker taking the risky job search strategy. However, it will be worthwhile for some young workers to take up the risky strategy, and this will be true for those whose ability is so high that the return over time of getting a wage job (which is the window to high paying selfemployment) more than balances the low probability of securing a wage job. This is regime I. As wage employment rises, parametrically, this probability rises, and pulls in lower ability young workers, until we get to young workers who will not enter entrepreneurship after wage employment, but the risk is still worthwhile for them because the probability of a wage job is sufficiently high. This is regime II. As wage employment and hence the probability of finding wage employment continues to rise, all young workers will be taking risk but no adults (among those who are not already in wage employment or highpaying self-employment) as yet--because young workers have two periods to reap the gains of getting lucky while adults have only one period left in their lives. We are now in regime III. This will go on until the gains from safety and risk are just matched for adult workers and we move to regime IV. Now the number of adult workers undertaking risky search will increase with wage jobs until all adult workers 
(who are not already in wage employment or high paying self-employment because of choices when they were young) are also searching. When this happens, we are in regime $\mathrm{V}$. The consequent division of wage employment between youth and adults is displayed in Figure 3.

An analogous story can be told for other parameters in the model, but the intuitive account for the case of wage employment increasing carries through for all. In fact, the wage employment story immediately gives an answer to the first of our questions: Does an increase in wage employment increase or decrease unemployment? The answer is that in the richer model the relationship between formal jobs and unemployment is non-monotonic. This is shown in Figures 2a and 2b. As wage employment increases from a low level, more youth undertake the risky search strategy (we are in regime I). If the number of high ability young workers undertaking risky search exceeds the increase in wage employment, higher unemployment ensues as in Figure 3a when the spread of worker ability is sufficiently narrow. But by contrast if the spread of worker ability is sufficiently wide, an increase in wage employment may draw in a smaller number of risky job seekers. The result is the possible nonmonotonicity within regime I as unemployment rises and falls with wage employment as shown in Figure $2 b$.

Now let us proceed to subsequent regimes. Once in regime II, the Harris-Todaro prediction higher wage employment increases unemployment - holds when the marginal risky job seeker is a low ability young worker. But the point comes where all the young are taking the risky strategy but adults are not, which marks regime III. Thus further increases in formal jobs will reduce unemployment. As formal jobs keep increasing and older workers enter risky search, the logic of regime II comes back and more jobs mean more unemployment. However, as wage employment keeps rising, eventually unemployment will also fall by the logic of regime III. So our model answers the first question but gives an answer which is at odds with Harris-Todaro: over certain ranges, unemployment can fall when formal wage unemployment increases. Further, the analysis delineates precisely when this happens and why.

We have already touched upon the answer to the second question: What does increasing wage employment do to youth unemployment? Our analysis shows a non-monotonic relationship, with ranges where increasing wage employment will indeed reduce youth unemployment (for example, in regime III and $\mathrm{V}$, with no change in youth unemployment in regime IV). As important, however, our analysis allows a differentiated analysis of youth unemployment and adult unemployment in response to different policy changes. In regimes I, II and III, for example, increasing wage employment affects youth unemployment but adult unemployment remains at zero throughout. In regime IV, however, increasing wage employment increases adult unemployment but does not affect youth unemployment. In regime 
V, at very high levels of wage employment, further increases in wage employment do indeed lead to falling unemployment among both adults and youth. These patterns are illustrated in detail in Figures $2 a$ and $2 b$.

The answer to the third question - among the self-employed, how many are able to become high-earning entrepreneurs and how many are confined to low-wage free-entry work? - is embodied in our earlier discussion as well. In regime I, only young workers of high enough ability adopt risky search, and of these, all those who find wage employment eventually become high paying entrepreneurs. In regimes II - V, the number of high ability workers who enter high paying entrepreneurship now additionally depends on the number of other workers (including low ability young workers in Regimes II and III, adult workers in Regimes IV and V) who also adopt risky search, and the resulting wage employment probability. Figure 4 illustrates that high paying self-employment is sometimes strictly increasing with respect to wage employment and is sometimes unchanged.

Turning to low wage free entry work, among young workers, these are workers who choose not to engage in risky search. Figure 5 illustrates the number of such workers as positive and strictly decreasing in wage employment in regimes I and II. Beyond regime II, there are no more young workers in free entry work for they either unemployed, or employed in wage employment. Among adult workers, low wage free entry self-employment applies to those who are (i) not employed as a wage worker, (ii) not employed as a high-paying entrepreneur, and (iii) not engaged in risky search. Consistent with these three reasons, Figure 5 shows adult low-wage self-employment to be decreasing in wage employment demand through regime IV. Then, in regime $\mathrm{V}$, some adult workers have already found wage employment and then moved up into high-paying entrepreneurship, other adult workers have already found wage employment and chosen to remain in wage employment, and all remaining adult workers engage in risky search, which results either in wage employment or unemployment. Consequently, no adult worker is in free-entry self-employment in this regime.

To summarize, across all regimes, only high-ability individuals undertake risky search to earn a chance to enter high-paying self-employment. As for low wage free entry work, it is adopted by all those young or adult job seekers who do not adopt risky search.

Taken together, our results provide two sets of insights that are to date underappreciated in multi-sectoral models of labor markets in developing economies. First, the original Harris-Todaro insights on the effectiveness of policies on labor market outcomes hold well when the relevant group of workers contemplating risky search is homogeneous in terms of ability, and has a static decision time frame so that their assessment of the gains and opportunity costs of risky search are both homogeneous 
and one shot. In our setting, regime IV fits this description exactly. By introducing heterogeneous ability, we introduce regime I, in which the marginal risky job seeker has high ability, and makes the decision on whether to engage in risky search depending on the relative costs and ability-specific gains from doing so. By introducing two age groups, we introduce regime II, in which the benefits and opportunity cost of risky search depends explicitly on the dynamic considerations. In regime III, we are at a corner where policies do not affect the extent of risky search for either generation: young workers are all choosing risky search and adult workers are all choosing safe search On the other hand, in regime $V$, we have the other corner solution: all job seekers, young and old alike, engage in risky search.

Second, our model also illustrates how aggregate labor market outcomes can mask much more nuanced comparative statics at the group / sub-group level. The unemployment responses of youth and adult workers to rising wage employment are good examples, where the two are shown to move in the same direction in one regime (V) and in different directions in others (regimes I - IV).

We hope our model has reinforced the value of multi-sector labor market modeling for developing countries while also demonstrating which earlier results are sustained and which are contradicted in an enriched structure. We look forward to extending this line of analysis in future work. 


\section{Table 1. Ex Ante and Ex Post Labor Market Equilibrium}

\begin{tabular}{|c|c|c|}
\hline & \multicolumn{2}{|c|}{ Ex-Ante } \\
\hline Regime & $\pi^{*}$ & $\mathcal{J}_{r}^{*} / \mathcal{L}$ \\
\hline & $+2 \rho \bar{\theta} \varepsilon_{W}$ & $\varepsilon_{W} w_{W}+\rho\left(w_{W}+\bar{\theta}-w_{F}\right)$ \\
\hline I $\Leftrightarrow \frac{\varepsilon_{W}}{\mathcal{L}} \in\left(0, \frac{\pi}{2}\right)$ & $\frac{w_{F}+\frac{\mathcal{L}}{w_{W}+\rho\left(w_{W}+\bar{\theta}-w_{F}\right)}}{}$ & $\overline{\mathcal{L}}\left(w_{F}+\frac{2 \rho \bar{\theta} \varepsilon_{W}}{\mathcal{L}}\right)$ \\
\hline$\| \Leftrightarrow \frac{\varepsilon_{W}}{\mathcal{L}} \in\left[\frac{\pi}{2}, \frac{3 \hat{\pi}}{2}\right)$ & $\hat{\pi}$ & $\frac{1}{2}\left(\frac{1}{\hat{\pi}} \frac{\mathcal{E}_{W}}{\mathcal{L}}+\frac{1}{2}\right)$ \\
\hline $\mathrm{III} \Leftrightarrow \frac{\varepsilon_{W}}{\mathcal{L}} \in\left[\frac{3 \hat{\pi}}{2}, \frac{3 \bar{\pi}}{2}\right)$ & $\frac{2}{3} \frac{\mathcal{E}_{W}}{\mathcal{L}}$ & 1 \\
\hline $\mathrm{IV} \Leftrightarrow \frac{\varepsilon_{W}}{\mathcal{L}} \in\left[\frac{3 \bar{\pi}}{2}, \bar{\pi}\left(\frac{5}{2}-\bar{\pi}\right)\right)$ & $\bar{\pi}$ & $\frac{1}{\bar{\pi}} \frac{\varepsilon_{W}}{\mathcal{L}}-\frac{1}{2}$ \\
\hline $\mathrm{V} \Leftrightarrow \frac{\varepsilon_{W}}{\mathcal{L}} \in\left[\bar{\pi}\left(\frac{5}{2}-\bar{\pi}\right), \frac{3}{2}\right]$ & $\frac{5}{4}-\sqrt{\left(\frac{5}{4}\right)^{2}-\mathcal{E}_{W} / \mathcal{L}}$ & $\frac{3}{4}+\sqrt{\left(\frac{5}{4}\right)^{2}-\mathcal{E}_{W} / \mathcal{L}}$ \\
\hline
\end{tabular}

Note: $\hat{\pi} \equiv w_{F} /\left(w_{W}(1+\rho)-\rho w_{F}\right)$ and $\left.\bar{\pi} \equiv w_{F} / w_{W}\right)$.

\begin{tabular}{|c|c|c|c|}
\hline & \multicolumn{3}{|c|}{ Ex-Post } \\
\hline Reg. & $U^{*} / \mathcal{L}$ & $\mathcal{E}_{H}^{*} / \mathcal{L}$ & $\mathcal{E}_{F}^{*} / \mathcal{L}$ \\
\hline \multirow[b]{2}{*}{ I } & $\underline{\varepsilon_{W}} \underline{w_{W}+\rho\left(w_{W}+\bar{\theta}-w_{F}\right)}-\underline{\varepsilon_{W}}$ & \multirow{2}{*}{$\frac{\mathcal{E}_{W}}{\mathcal{L}}$} & \multirow{2}{*}{$2-\frac{\mathcal{E}_{W}}{\mathcal{L}}-\frac{\mathcal{E}_{W}}{\mathcal{L}} \frac{w_{W}+\rho\left(w_{W}+\bar{\theta}-w_{F}\right)}{w_{F}+\frac{2 \bar{\theta} \rho \varepsilon_{W}}{\mathcal{L}}}$} \\
\hline & $\overline{\mathcal{L}} \overline{\left(w_{F}+\frac{2 \rho \bar{\theta} \varepsilon_{W}}{\mathcal{L}}\right)}-\overline{\mathcal{L}}$ & & \\
\hline \multirow{2}{*}{ II } & \multirow{2}{*}{$\frac{1-\hat{\pi}}{2}\left(\frac{1}{\hat{\hat{n}}} \frac{\mathcal{E}_{W}}{\Omega}+\frac{1}{2}\right)$} & \multirow{2}{*}{$\frac{\hat{\pi}}{2}$} & \multirow{2}{*}{$2-\frac{1+\hat{\pi}}{2 \hat{\varepsilon}} \frac{\varepsilon_{W}}{s}-\frac{1+\hat{\pi}}{2}$} \\
\hline & & & \\
\hline III & $\left(1-\frac{2}{3} \frac{\varepsilon_{W}}{\Gamma}\right)$ & $\frac{1}{3} \frac{\varepsilon_{W}}{r}$ & $\frac{2 \pi}{1-\frac{2}{3}} \frac{\varepsilon_{W}}{\Gamma}$ \\
\hline IV & $(1-\bar{\pi})\left(\frac{1}{\bar{\pi}} \frac{\mathcal{E}_{W}}{\mathcal{L}}-\frac{1}{2}\right)$ & $\frac{\bar{\pi}}{2}$ & $(2-\bar{\pi})-\left(\frac{1}{\bar{\pi}} \frac{\varepsilon_{W}}{\mathcal{L}}-\frac{1}{2}\right)$ \\
\hline V & $\left.-\frac{1}{4}+\sqrt{\left(\frac{5}{4}\right)^{2}-\frac{\mathcal{E}_{W}}{\mathcal{L}}}\right)\left(\frac{3}{4}+\sqrt{\left(\frac{5}{4}\right)^{2}-\frac{\mathcal{E}_{W}}{\mathcal{L}}}\right.$ & $\frac{1}{2}\left(\frac{5}{4}-\sqrt{\left(\frac{5}{4}\right)^{2}-\frac{\mathcal{E}_{W}}{\mathcal{L}}}\right)$ & 0 \\
\hline
\end{tabular}


Table 2. Comparative Statics: High-Wage Employment, Ex Ante and Ex Post Labor Allocations

\begin{tabular}{|c|c|c|c|c|c|}
\hline Regime & \multicolumn{5}{|c|}{ Impact of raising $\mathcal{E}_{W}$ on: } \\
\hline & $\mathcal{J}_{r}^{*}$ & $\mathcal{U}^{*}$ & $\mathcal{E}_{W}^{*}$ & $\mathcal{E}_{H}^{*}$ & $\mathcal{E}_{F}^{*}$ \\
\hline I & + & + or inverted U & + & + & - \\
\hline II & + & + & + & 0 & - \\
\hline III & 0 & - & + & + & - \\
\hline IV & + & + & + & 0 & 0 \\
\hline V & - & - & + & + & \\
\hline
\end{tabular}




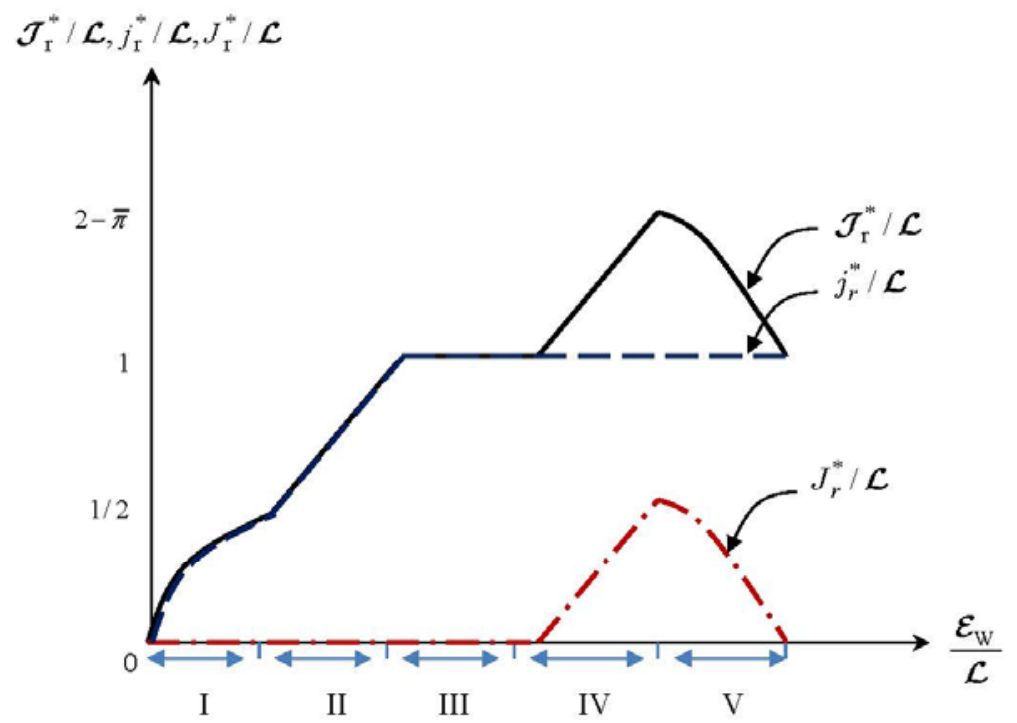

Figure 1.

Equilibrium Risky Job Search 


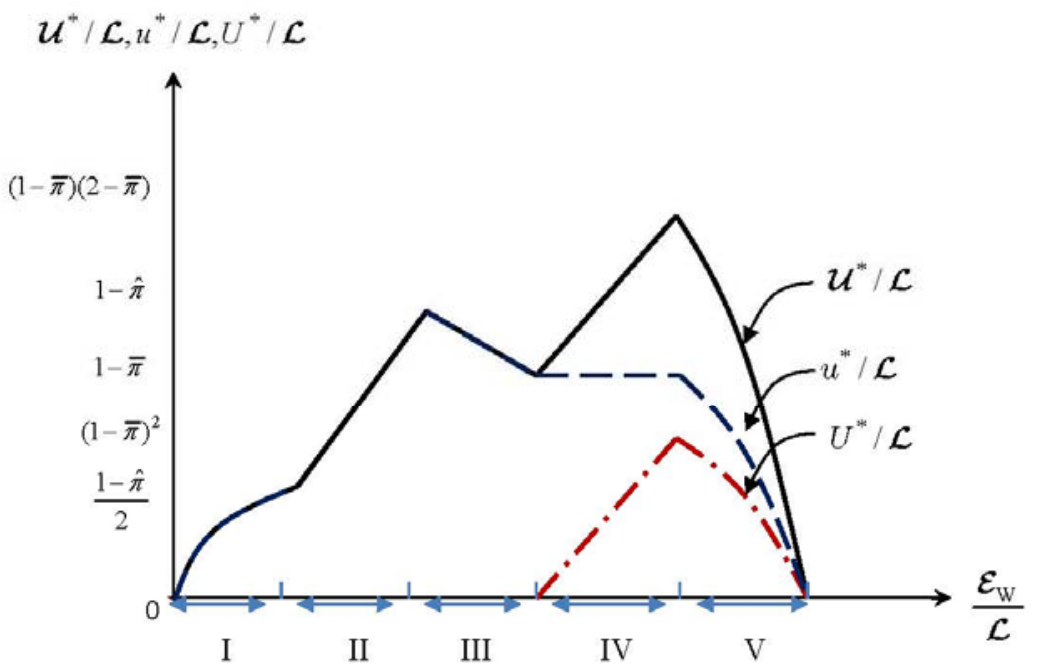

Figure 2a.

Total Unemployment, Youth Unemployment and Adult Unemployment, with small spread in $\theta$

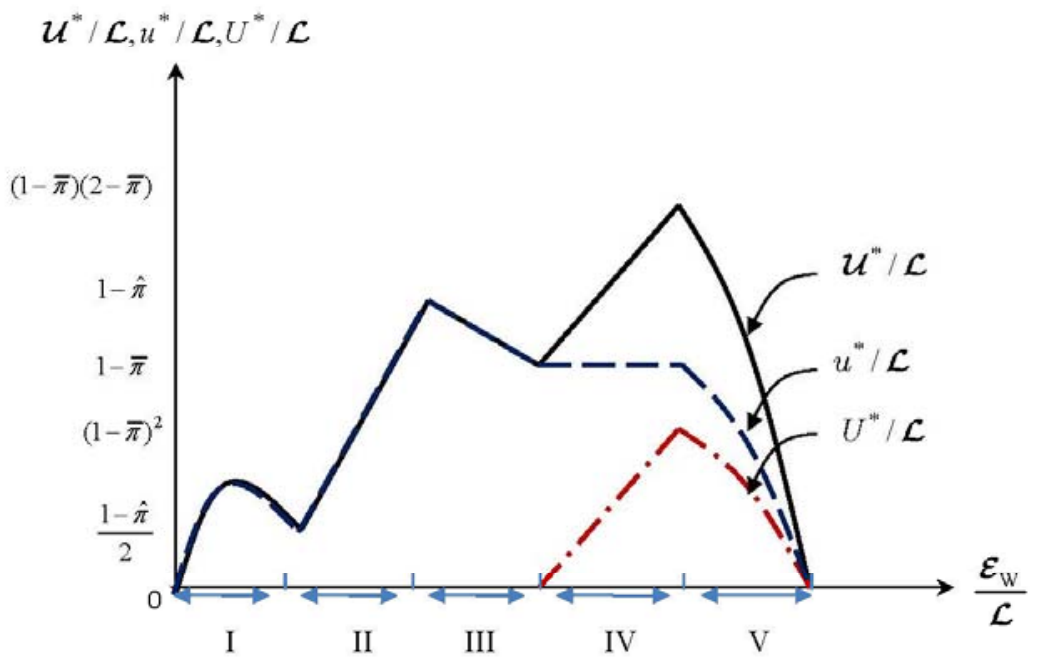

Figure 2b.

Total Unemployment, Youth Unemployment and Adult Unemployment, with large spread in $\theta$ 


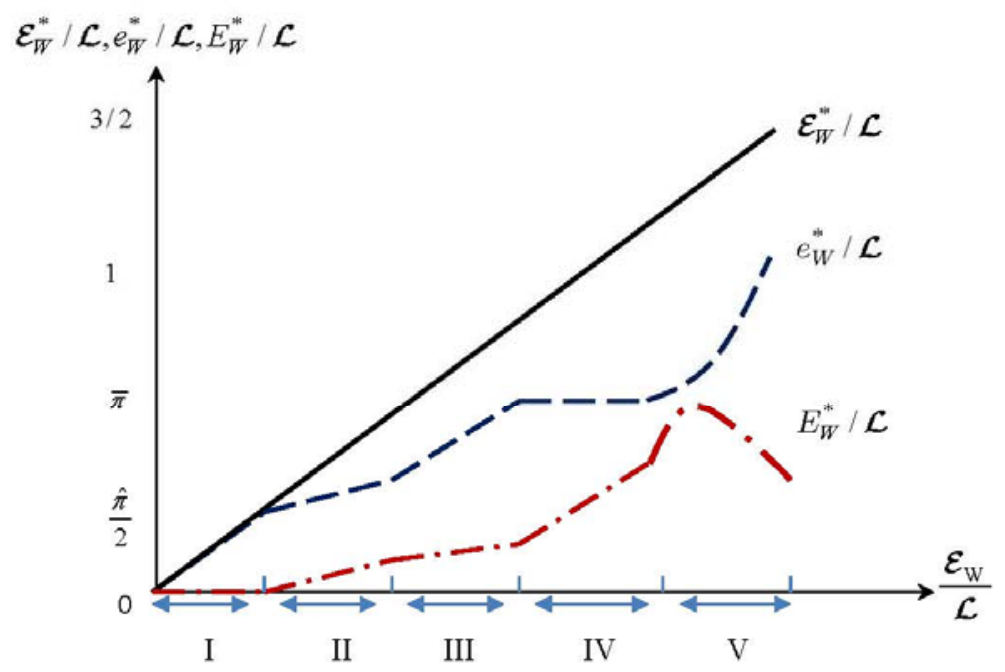

Figure 3.

Total Wage Employment, Adult Wage Employment and Youth Wage Employment

$\mathcal{E}_{H}^{*} / \mathcal{L}, e_{H}^{*} / \mathcal{L}, E_{H}^{*} / \mathcal{L}$

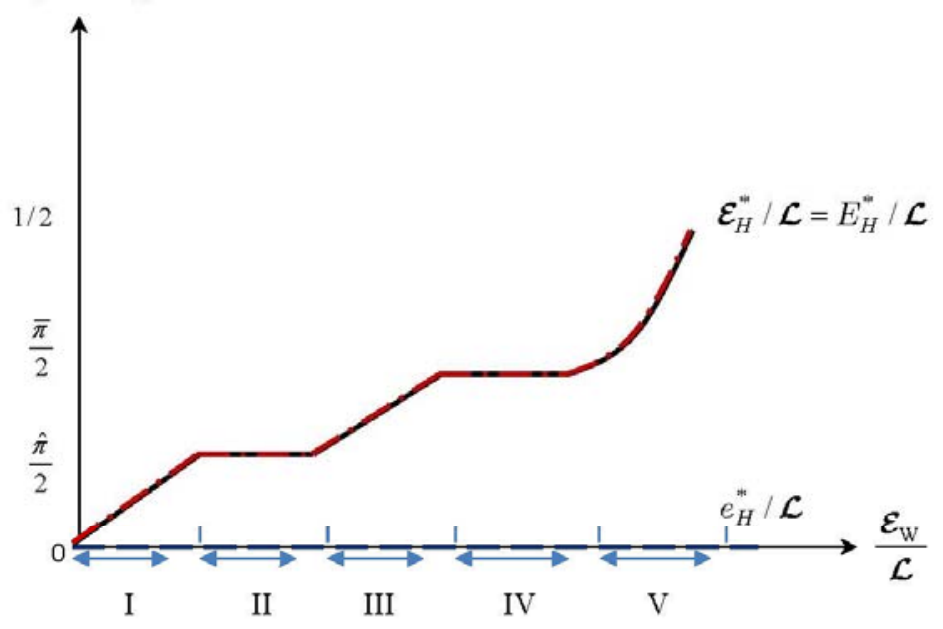

Figure 4.

Total High-Paying Self-Employment, Adult High-Paying Self-Employment And Youth High-Paying Self-Employment 


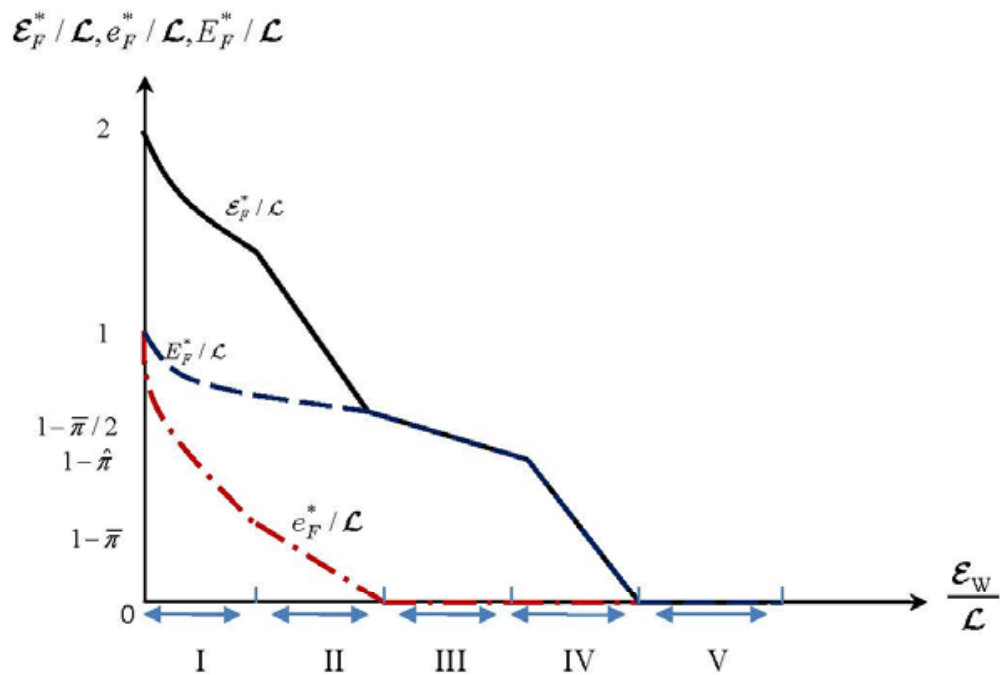

Figure 5.

Total Free Entry Self-Employment, Adult Free Entry Self-Employment and Youth Free Entry Self-Employment 


\section{References}

Akerlof, George A. 1976. "The Economics of Caste and of the Rat Race and Other Woeful Tales," The Quarterly Journal of Economics 90(4): 599-617.

Arellano, Josè-Paulo. 1981. "Do More Jobs in the Modern Sector Increase Urban Unemployment," Journal of Development Economics 8: 241-247.

Balán, Jorge, Harley L. Browning, and Elizabeth Jelin. 1973. Men in a Developing Society. Institute of Latin American Studies, University of Texas at Austin.

Becker, Gary. 1964. Human Capital. New York: Columbia University Press.

Bennett, John and Matthew D. Rablen. 2012. "Self-Employment, Wage Employment and Informality in a Developing Economy," IZA Discussion Paper 6406.

Bosch, Mariano and William F. Maloney. 2010. "Comparative Analysis of Labor Market Dynamics Using Markov Processes: An Application to Informality," Labour Economics 17(4): 621-631.

Chen, Martha. 2006. "Rethinking the Informal Economy: Linkages with the Formal Sector and the Formal Regulatory Environment." In Basudeb Guha-Khasnobis, Ravi Kanbur and Elinor Ostrom (Eds.). 2006. Linking the Formal and Informal Economy: Concepts and Policies. Oxford University Press, pp 75-92.

Duryea, Suzanne, Gustavo Márquez, Carmen Pagés and Stefano Scarpetta. 2006. "For Better or for Worse? Job and Earnings Mobility in Nine Middle- and Low-Income Countries." Brookings Trade Forum, Global Labor Markets. pp. 187-209.

Fields, Gary S.. 1974. "The Private Demand for Education in Relation to Labour Market Conditions in Less-Developed Countries," The Economic Journal 84(336): 906-925.

Fields, Gary S. 1975. "Rural-Urban Migration, Urban Unemployment and Underemployment, and Job Search Activity in LDC's," Journal of Development Economics 2: 165-188.

Fields, Gary S. 1989. "On-the-Job Search in a Labor Market Model: Ex-Ante Choices and Ex-Post Outcomes," Journal of Development Economics 30: 159-178.

Fields, Gary S. (1990). "Labour Market Modeling and the Urban Informal Sector: Theory and Evidence," in David Turnham, Bernard Salomé, and Antoine Schwarz, eds., The Informal Sector Revisited. Development Centre of the Organisation for Economic Co-Operation and Development, Paris.

Harris, John and Michael Todaro (1970). "Migration, Unemployment, and Development: A Two Sector Analysis," American Economic Review 40: 126-142. 
Jütting, Johannes, Jante Parlevliet and Theodora Xenogiani. 2008. "Informal Employment Re-loaded," OECD Development Centre Working Paper 266.

Lall, Somik V., Harris Selod, and Zmarak Shalizi. 2006. "Rural-Urban Migration in Developing Countries: A Survey of Theoretical Predictions and Empirical Findings," World Bank Policy Research Working Paper 3915.

Lehmann, Hartmut, and Norberto Pignatti. 2007. "Informal Employment Relationships and Labor Market Segmentation in Transition Economies: Evidence from Ukraine,“ IZA Discussion Paper 3269.

Lewis, Arthur W. 1954. "Economic Development with Unlimited Supplies of Labour," Manchester School 22: 139-191.

Maloney, William F., 2004. "Informality Revisited," World Development 32(7): 1159-1178.

Perry, Guillermo E., William F. Maloney, Omar S. Arias, Pablo Fajnzylber, Andrew D. Mason and Jaime Saavedra-Chanduvi. 2007. Informality: Exit and Exclusion. The World Bank, Washington D.C.

Schultz, Theodore W. 1961. "Investing in Human Capital." American Economic Review 51: 1-17.

Spence, Michael, 1973. “Job Market Signalling," The Quarterly Journal of Economics 87, No. 3: 355-374.

Stiglitz, J. E. 1975. "The Theory of Screening, Education and the Distribution of Income."American Economic Review 65 (3): 283-300.

Steel, William F. and Yasuoki Takagi. 1983. "Small Enterprise Development and the Employment Output Trade-off," Oxford Economic Papers 35:. 423-446.

Todaro, Michael P. 1969. "A Model of Labor Migration and Urban Unemployment in Less Developed Countries," American Economic Review 39: 138-148.

Zarembka, Paul. 1970. "Labor Migration and Urban Unemployment: Comment," American Economic Review 60: 184-186.

Zenou, Yves. 2011. "Rural-Urban Migration and Unemployment: Theory and Policy Implications," Journal of Regional Science 51(1): 65-82. 